\title{
Efficacy of vitamin and antioxidant supplements in prevention of cardiovascular disease: systematic review and meta-analysis of randomised controlled trials
}

\author{
(c) 1 (1) (8) OPEN ACCESS
}

\author{
Seung-Kwon Myung senior scientist ${ }^{12}$, Woong Ju associate professor ${ }^{3}$, Belong Cho professor ${ }^{1}$, \\ Seung-Won Oh assistant professor ${ }^{4}$, Sang Min Park associate professor ${ }^{1}$, Bon-Kwon Koo associate \\ professor $^{5}$, Byung-Joo Park professor ${ }^{6}$, for the Korean Meta-Analysis (KORMA) Study Group
}

${ }^{1}$ Department of Family Medicine, Seoul National University College of Medicine, Seoul, Republic of Korea; ${ }^{2}$ Carcinogenesis Research Branch and Department of Family Medicine, Research Institute and Hospital, National Cancer Center, Goyang, Republic of Korea; ${ }^{3}$ Department of Obstetrics and Gynecology and Medical Research Institute, College of Medicine, Ewha Womans University, Seoul, Republic of Korea; ${ }^{4}$ Healthcare Research Institute and Department of Family Medicine, Healthcare System Gangnam Center, Seoul National University Hospital, Seoul, Republic of Korea; ${ }^{5}$ Department of Internal Medicine, Seoul National University Hospital, Seoul, Republic of Korea; ${ }^{6}$ Department of Preventive Medicine, Seoul National University College of Medicine, Seoul, Republic of Korea

\begin{abstract}
Objective To assess the efficacy of vitamin and antioxidant supplements in the prevention of cardiovascular diseases.

Design Meta-analysis of randomised controlled trials.

Data sources and study selection PubMed, EMBASE, the Cochrane Library, Scopus, CINAHL, and ClinicalTrials.gov searched in June and November 2012. Two authors independently reviewed and selected eligible randomised controlled trials, based on predetermined selection criteria.

Results Out of 2240 articles retrieved from databases and relevant bibliographies, 50 randomised controlled trials with 294478 participants (156 663 in intervention groups and 137815 in control groups) were included in the final analyses. In a fixed effect meta-analysis of the 50 trials, supplementation with vitamins and antioxidants was not associated with reductions in the risk of major cardiovascular events (relative risk $1.00,95 \%$ confidence interval 0.98 to $1.02 ; l^{2}=42 \%$ ). Overall, there was no beneficial effect of these supplements in the subgroup meta-analyses by type of prevention, type of vitamins and antioxidants, type of cardiovascular outcomes, study design, methodological quality, duration of treatment, funding source, provider of supplements, type of control, number of participants in each trial, and supplements given singly or in combination with other supplements. Among the subgroup meta-analyses by type of cardiovascular outcomes, vitamin and antioxidant supplementation was associated with a marginally increased risk of
\end{abstract}

angina pectoris, while low dose vitamin $\mathrm{B}_{6}$ supplementation was associated with a slightly decreased risk of major cardiovascular events. Those beneficial or harmful effects disappeared in subgroup meta-analysis of high quality randomised controlled trials within each category. Also, even though supplementation with vitamin $\mathrm{B}_{6}$ was associated with a decreased risk of cardiovascular death in high quality trials, and vitamin E supplementation with a decreased risk of myocardial infarction, those beneficial effects were seen only in randomised controlled trials in which the supplements were supplied by the pharmaceutical industry.

Conclusion There is no evidence to support the use of vitamin and antioxidant supplements for prevention of cardiovascular diseases.

\section{Introduction}

Cardiovascular diseases are the leading causes of deaths and disability worldwide. ${ }^{1}$ Over the past few decades, observational epidemiological studies have reported that intake of fruit and vegetables rich in various vitamins and antioxidants reduce the risk. ${ }^{2}$ It has been estimated that if an individual increases fruit and vegetable intake up to $600 \mathrm{~g}$ daily, the worldwide burden of disease could be reduced by $31 \%$ for ischaemic heart disease and $19 \%$ for ischaemic stroke. ${ }^{3}$ Unlike the evidence for fruit and vegetables, however, many randomised controlled trials have reported inconsistent findings regarding the efficacy of 
vitamin and antioxidant supplementation on cardiovascular diseases. $^{4}$

Several meta-analyses have reported conflicting evidence from randomised controlled trials. In 2003, a meta-analysis of 12 trials indicated that vitamin $\mathrm{E}$ supplements did not provide benefit in cardiovascular death or cerebrovascular events. ${ }^{5}$ Instead, it showed that $\beta$ carotene supplementation led to a small increase in all cause mortality and cardiovascular death. In 2006, Flores-Mateo et al reported that the use of supplements containing selenium did not reduce the risk of coronary heart disease in the meta-analysis of six trials. ${ }^{6}$ More recently, however, Lee et al found that folic acid supplementation with $B$ vitamins had potential small benefits in the prevention of stroke, ${ }^{7}$ and Qin et al indicated that folic acid treatment decreased the risk of cardiovascular disease by $15 \%$ in patients with end stage renal disease or advanced chronic kidney disease. ${ }^{8}$ Even though several meta-analyses of randomised controlled trials have been published regarding the efficacy of vitamins and antioxidant supplements on cardiovascular diseases, they involved individual vitamins or antioxidants, and there was no published comprehensive meta-analysis that reviewed this topic all together in one report. To the best of our knowledge, no meta-analyses have performed subgroup analyses by important factors such as methodological quality or funding source.

We investigated the efficacy of vitamin and antioxidant supplements on cardiovascular diseases through a comprehensive meta-analysis of randomised controlled trials by various factors such as by type of prevention (primary $v$ secondary), type of vitamins and antioxidants, dose of supplement, type of cardiovascular outcomes, study design, methodological quality (high $v$ low), duration of treatment $(<5$ years $v \geq 5$ years), funding source (independent organisation $v$ pharmaceutical industry), provider of supplements (pharmaceutical industry $v$ not pharmaceutical industry), type of control (placebo $v$ no placebo), number of participants in each trial $(<10000 v \geq 10000)$, and supplements given singly or in combination with other vitamin or antioxidant supplements.

\section{Methods}

\section{Literature search}

We searched PubMed, Embase, the Cochrane Library, Scopus, CINAHL, and ClinicalTrials.gov in June and November 2012 using common keywords related to vitamin or antioxidant supplements and cardiovascular diseases. The keywords were as follows: "vitamin supplement," "antioxidant supplement," "vitamin A supplement," "vitamin $\mathrm{B}_{6}$ supplement," "vitamin $\mathrm{B}_{12}$ supplement," "folic acid supplement," "vitamin C supplement," "vitamin D supplement," "vitamin E supplement," "selenium supplement," "beta-carotene supplement," "lycopene supplement," or "isoflavone supplement,"; and "cardiovascular disease," "angina," "acute myocardial infarction," "transient ischemic attack," or "stroke." We also reviewed the bibliographies of relevant articles to locate additional publications. The language of publication was not restricted.

\section{Selection criteria}

To be included randomised controlled trials had to report the efficacy of vitamin or antioxidant supplements for the prevention of cardiovascular diseases and follow participants for at least six months. If data were duplicated or shared in more than one study, we included the first published or more comprehensive study in the analysis.

\section{Selection of relevant studies}

Based on the predetermined selection criteria, two of the authors (S-KM, WJ) independently selected all trials retrieved from the databases and bibliographies. Disagreements were resolved by discussion or in consultation with a third author (S-WO).

\section{Assessment of methodological quality}

We assessed the methodological quality of included trials with the Jadad scale. ${ }^{9}$ Its score ranges from 0 (very poor) to 5 (rigorous). The five point quality scale consists of points for randomisation (described as randomised, 1 point; table of random numbers or computer generated randomisation, additional 1 point), double blind (described as double blind, 1 point; use masking such as identical placebo, additional 1 point), and follow-up (state the numbers and reasons for withdrawal in each group; 1 point) in the report of each trial. All trials were classified into two groups, those with a score of $\leq 4$ or versus 5 because the mean score for the 47 trials assessed in the current study (the full text for three trials was not available) was 4.3, and then subgroup meta-analyses were performed.

\section{Main and subgroup analyses}

We investigated the association between vitamin or antioxidants supplementation and major cardiovascular events. Major cardiovascular events included cardiovascular death, fatal or non-fatal myocardial infarction, angina, sudden cardiac death, fatal or non-fatal stroke, and transient ischaemic attack. We also performed subgroup meta-analyses by type of prevention (primary $v$ secondary: in this study, trials involving healthy populations or patients with any specific disease except for cardiovascular disease were classified as primary prevention trials, and trials involving patients with cardiovascular disease were classified as secondary prevention trials), type of supplement by quality and dose (each supplement, vitamins only, antioxidants only, or antioxidants excluding vitamins), type of outcome (cardiovascular death, angina, fatal or non-fatal myocardial infarction, stroke, or transient ischaemic attack), type of outcome in each supplement, type of study design (randomised, double blind, placebo controlled trial $v$ open label, randomised controlled trial), methodological quality (high $v$ low), duration of treatment ( $<5$ years $v \geq 5$ years), funding source (pharmaceutical industry $v$ independent organisation), provider of supplements (pharmaceutical industry $v$ not pharmaceutical industry), type of control (placebo $v$ no placebo), number of participants $(\geq 10000 v<10000)$, and supplements given singly or in combination with other vitamin or antioxidant supplements by quality.

\section{Statistical analysis}

We calculated the relative risks with $95 \%$ confidence intervals by using crude $2 \times 2$ tables on the basis of intention to treat analysis, whenever possible, from the original publications. For the test of heterogeneity, we used Higgins $\mathrm{I}^{2}$, which measures the percentage of total variation across trials. ${ }^{10} \mathrm{I}^{2}$ was calculated as follows:

$\mathrm{I}^{2}=100 \% \times(\mathrm{Q}-\mathrm{df}) / \mathrm{Q}$,

where $\mathrm{Q}$ is Cochran's heterogeneity statistic and df indicates the degrees of freedom. Negative values of $\mathrm{I}^{2}$ are set to zero. $\mathrm{I}^{2}$ ranges from $0 \%$ (no observed heterogeneity) to $100 \%$ (maximal heterogeneity).

To calculate pooled relative risks with $95 \%$ confidence intervals, we used both the fixed effects and random effects models. An $\mathrm{I}^{2}$ value $>50 \%$ was considered as substantial heterogeneity. 
When there was no substantial heterogeneity, we reported the pooled estimate calculated from the fixed effects model. When there was substantial heterogeneity, we reported the pooled estimate calculated from the random effects model.

We assessed publication bias with Begg's funnel plot and Egger's test. If publication bias exists, the Begg's funnel plot is asymmetric or the Egger's test $P$ value is $<0.05$. We used Stata SE version 10.0 software (StataCorp, College Station, TX) for all the statistical analyses.

\section{Results}

By searching databases (PubMed, Embase, the Cochrane Library, Scopus, CINAHL, and ClinicalTrials.gov) and hand searching relevant bibliographies, we identified 2240 articles (fig $1 \Downarrow$ ). After excluding 573 duplicated articles, two of authors independently reviewed and excluded 1593 articles that did not satisfy the predetermined selection criteria based on each article's title and abstract. We reviewed the full texts of the 74 remaining articles and excluded 24 articles (16 were identical trials within the same population; five were not related to the subject of this study; two were replies or comments; and one reported insufficient data). A total of $50^{11-60}$ trials were included in the final analysis. The full details of all included trials are in appendix 1. The 50 trials included 294478 participants with 156663 in intervention groups and 137815 in control groups. In the trials reporting age, the mean age of the participants ranged from 49 to 82 . The year of publication of the included trials ranged between 1989 and 2012, spanning 23 years. Twelve trials were conducted in the United State, four in the United Kingdom, three in Finland, three in France, three in Italy, two in Canada, two in Israel, two in Australia, two in China, two in Germany, two in Norway, one in Sweden, one in Switzerland, one in the Netherlands, one in US/Canada, one in

US/Canada/Scotland), one in Germany/the Netherlands, one in Canada/US, one in 13 countries, and one in 20 countries. The range of supplementation and follow-up periods was 6 months to 12 years. The number of participants ranged from 61 to 39 876.

Among the 50 trials, 30 were primary prevention trials (general populations, smokers and workers exposed to asbestos, patients with oesophageal dysplasia, male physicians, patients with non-melanoma skin cancer, postmenopausal women, patients undergoing chronic haemodialysis, patients with end stage renal disease, ambulatory elderly women with vitamin D insufficiency, patients with chronic renal failure, older people with femoral neck fractures, patients with diabetes mellitus, elderly women with a low serum 25 -hydroxyvitamin D concentration, health professionals, people with a high fasting plasma total homocysteine concentration, or kidney transplant recipients), and 20 were secondary prevention trials (patients with cardiovascular disease, coronary heart disease, acute myocardial infarction, unstable angina, transient ischaemic attack, stroke, angiographically proved coronary atherosclerosis, vascular disease, or aortic valve stenosis).

Forty five trials were randomised, double blind, placebo controlled trials, and five were open label, randomised controlled trials. All vitamin or antioxidant supplements and placebos were administered orally either singly or in combination with other vitamin or antioxidant supplements.

The dose regimens used in each trial were as follows: vitamin A (10 000 or 25000 IU daily), vitamin $\mathrm{B}_{6}(3,6,10,12.5,25$, $40,48,50$, or $100 \mathrm{mg}$ daily; $20 \mathrm{mg}$ three times weekly), vitamin $\mathrm{B}_{12}(0.4,0.5,1$, or $2 \mathrm{mg}$ daily; $6,18,20,60$, or $400 \mu \mathrm{g}$ daily; 50 $\mu \mathrm{g}$ three times weekly), vitamin C $(60,120,180,250,500$, or
$1000 \mathrm{mg}$ daily), vitamin D (800 or 1000 IU daily; 200 IU twice daily; 400 IU twice daily; 300 IU daily and 100 IU daily; 100 000 IU every four months), vitamin E (60, 200, 400, 600, 800 IU daily; 400 or 600 IU alternate day; 400 IU twice daily; 30, $50,300,600 \mathrm{mg}$ daily), $\beta$ carotene $(6,15,20,25,30$, or $50 \mathrm{mg}$ daily; $50 \mathrm{mg}$ alternate day), folic acid ( 560 or $800 \mu \mathrm{g}$ daily; 0.5 , $0.8,1,1.2,2,2.5,5,15$, or $40 \mathrm{mg}$ daily; $5 \mathrm{mg}$ three times weekly), and selenium $(50,75,100,122$, or $122 \mu \mathrm{g}$ daily).

Thirty nine trials used vitamin supplements only, and 22 trials used antioxidant supplements only. The additional nutritional supplements or drugs used in each trial were aspirin $(325 \mathrm{mg}$ daily); coenzyme Q10 (100 mg daily); calcium (93 mg daily) with or without hormone replacement therapy; application of a sun protection factor 15+ sunscreen; ramipril (angiotensin converting enzyme inhibitor; with or without aspirin (100 mg daily); zinc (20 mg daily); multivitamins and minerals; calcium carbonate (500 mg twice daily); calcium (1000 mg daily); calcium citrate (1000 mg daily); omega 3 fatty acids (eicosapentaenoic acid and docosahexaenoic acid at a ratio of 2:1). The main outcomes used in each trial were fatal or non-fatal acute myocardial infarction, unstable angina, coronary heart disease, ischaemic heart disease, major coronary events, cardiovascular death, sudden death, transient ischaemic stroke, stroke, and cardiovascular disease.

Out of 47 trials reporting funding source, five were funded by pharmaceutical companies and 42 were funded mainly by public or governmental organisations or independent scientific foundations. Also, in 29 trials, vitamin or antioxidant supplements were provided at no cost from the pharmaceutical industry, while 18 trials paid for them or did not mention whether the pharmaceutical industry charged for them.

In the fixed effects meta-analysis of all 50 trials, use of vitamin or antioxidant supplements was not associated with reduced risks of major cardiovascular events (relative risk 1.00; 95\% confidence interval 0.98 to $1.02 ; \mathrm{I}^{2}=42 \%$ ) (fig $2 \Downarrow$ ). Overall, the effect sizes of the smaller randomised controlled trials tend to be less than 1.0, while the effect sizes of the larger ones tend to be null. In the 48 selected trials, the Begg's funnel plot was symmetrical, and P for bias was 0.11 in the Egger's test (two ${ }^{12} 22$ of the 50 trials were not included because of "zero" cells in the $2 \times 2$ table) (the Begg's funnel plot is not shown in the figure).

Based on the Jadad scales, the mean score for the 47 trials assessed was 4.3 , ranging from 2 to 5 (table $1 \Downarrow$ ).

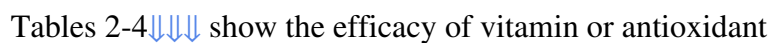
supplements in the prevention of the major cardiovascular events in subgroup meta-analysis by various factors. Overall, subgroup meta-analyses by type of supplement (table 2 ) $\Downarrow$ showed that there was no significant association between vitamin or antioxidant supplements and the risk of the major cardiovascular events (figs 3-6, $\Downarrow \Downarrow \Downarrow \Downarrow$ and table $2 \Downarrow$ ), while low dose vitamin $B_{6}$ supplementation slightly decreased the risk of major cardiovascular events (relative risk $0.92,95 \%$ confidence interval 0.85 to $0.99 ; \mathrm{I}^{2}=35 \%$; fig $7 \Downarrow$ ) in the fixed effects meta-analysis. Similarly, we found no significant association in the overall subgroup meta-analysis by type of outcome (cardiovascular death, fatal or nonfatal myocardial infarction, stroke, or transient ischaemic attack; table $3 \Downarrow$ ), type of prevention (primary $v$ secondary; table $2 \Downarrow$ ), type of study design, methodological quality (high $v$ low by score of 5), duration of treatment ( $<5$ years $v \geq 5$ years), funding source (independent organisation $v$ pharmaceutical industry) (table $4 \Downarrow$ ), and provider of the supplements (pharmaceutical industry $v$ at cost or no mention), while vitamin $\mathrm{B}_{6}$ and vitamin $\mathrm{E}$ supplements were associated with a reduced risk of cardiovascular death (relative 
risk $0.91,95 \%$ confidence interval 0.83 to $0.99 ; \mathrm{I}^{2}=0 \%$ ) and myocardial infarction $\left(0.77,0.65\right.$ to $\left.0.91 ; \mathrm{I}^{2}=76 \%\right)$, respectively, and vitamin and antioxidant supplementation marginally increased the risk of angina pectoris $\left(1.04,1.00\right.$ to $\left.1.08 ; \mathrm{I}^{2}=36 \%\right)$ (table $3 \Downarrow$ ).

In the subgroup meta-analysis of high quality randomised controlled trials within each category of low dose vitamin $\mathrm{B}_{6}$ (relative risk $0.94,95 \%$ confidence interval 0.87 to 1.02 ; $\mathrm{I}^{2}=39 \%$; fixed effects model, table $2 \Downarrow$ and fig $7 \Downarrow$ ) and angina (1.01, 0.86 to $1.18 ; \mathrm{I}^{2}=57 \%$; random effects model, table $3 \Downarrow$ ), however, beneficial or harmful effects disappeared. Also, even though vitamin $\mathrm{B}_{6}$ supplementation was associated with decreased risks of cardiovascular death in high quality trials, and vitamin E supplementation with a decreased risk of myocardial infarction, those beneficial effects were seen only in trials supplied with supplements by pharmaceutical industry (fig $8 \Downarrow$ and table $3 \Downarrow$ ).

In the subgroup meta-analysis by the number of participants in each trial, vitamin or antioxidant supplements showed a trend toward a decreased (but not significant) risk of major cardiovascular events (relative risk $0.97,95 \%$ confidence interval 0.94 to $1.01 ; \mathrm{I}^{2}=40 \%$ ) in the subgroup meta-analysis of trials with $<10000$ participants, while those supplements showed an increased (but not significant) risk of the major cardiovascular events $\left(1.02,0.99\right.$ to $\left.1.04 ; \mathrm{I}^{2}=39 \%\right)$ in the subgroup meta-analysis of those with $\geq 10000$ participants (table $4 \Downarrow$ ).

Table $5 \Downarrow$ shows the efficacy of vitamin and antioxidant supplements given singly or in combination with other vitamin or antioxidant supplements on major cardiovascular events in subgroup meta-analyses. We found no significant beneficial effect of vitamin and antioxidant supplements in most of the subgroup meta-analyses, while only vitamin E supplements had a marginally significant decreased efficacy for the major cardiovascular events in high quality trials (relative risk 0.95, $95 \%$ confidence interval 0.90 to $1.00 ; \mathrm{I}^{2}=45 \%$ ).

\section{Discussion}

\section{Summary of main findings}

In this large scale meta-analysis of randomised controlled trials, we found no evidence to support the use of vitamin or antioxidant supplements for the primary or secondary prevention of major cardiovascular events. Furthermore, these supplements were not associated with any reduced risk of the such events in the subgroup meta-analyses according to various factors such as type of vitamins and antioxidants, type of cardiovascular outcomes, study design, methodological quality, duration of treatment, funding source, provider of supplements, type of control, number of participants in each trial, and supplements given singly or in combination with other vitamins or antioxidant supplements.

\section{Strengths of the current meta-analysis}

Our main findings are consistent with those of previous meta-analyses that investigated the association between the use of vitamin $B,{ }^{76162}$ vitamin $D,{ }^{63}$ vitamin $E,{ }^{564} \beta$ carotene, ${ }^{5}$ folic acid, $^{78616266}$ or selenium $^{6}$ and cardiovascular diseases in randomised controlled trials.

Our findings, however, are inconsistent with those of previous in vivo animal studies that suggested vitamins or antioxidants inhibit the development of atherosclerosis ${ }^{67-70}$ and in vitro laboratory studies that indicated vitamins and antioxidants reduce lipid peroxidation and free radical damage, and finally inhibit atheroslcerosis. ${ }^{71-73}$ The findings from animal and laboratory studies are associated with the oxidative modification hypothesis of atherosclerosis. This hypothesis, which claims that the oxidation of low density lipoprotein cholesterol initiates atherosclerosis, could explain these associations. ${ }^{70}$ It suggests that accumulated low density lipoprotein in the subendothelial space of arteries is oxidised to minimally modified low density lipoprotein by vascular cells, which then induces accumulation of monocytes and macrophages, which stimulate further peroxdiation of low density lipoprotein. ${ }^{74}$ This reaction makes oxidised low density lipoprotein more negatively charged and completely oxidised. ${ }^{75}$ The uptake of completely oxidised low density lipoprotein leads to massive uptake of cholesterol by the macrophages. ${ }^{70}$ It also stimulates the binding of monocytes to the endothelium, promotes the release of lipids and lysosomal enzymes, and thus enhances the progression of atherosclerosis. $^{70} 76$

Our meta-analysis indicates that there is a discrepancy in findings between in vivo animal or in vitro laboratory studies and randomised controlled trials with regard to the association between vitamin or antioxidants (natural forms in fruit and vegetables or synthetic forms) and cardiovascular disease. Several theories could explain this discrepancy. Firstly, preclinical studies such as animal studies and in vitro laboratory studies might not represent the biological processes in the human body. ${ }^{73}$ Thus, even though vitamins or antioxidant substances show benefits against a certain disease in preclinical studies, they might show no benefit or could be harmful under clinical circumstances. Secondly, the beneficial effects of vitamin or antioxidant supplements might be related to the timing of their administration. For example, the beneficial effects vitamin C occur in the early stages of atherosclerosis, ${ }^{73}$ and once the atherosclerotic plaque has developed it has no beneficial effect. ${ }^{77}$ In the trials we included in our analysis, the mean age of participants ranged from 49 to 82 , the ages at which atherosclerotic plaques or changes might be already formed. ${ }^{73}$

We found a similar discrepancy in findings between case-control studies and randomised controlled trials. This could be explained by methodological biases of case-control studies. Case-control studies use retrospective assessment of each participant's information on fruit and vegetable consumption and are thus susceptible to two potential biases: recall and selection.

Even though cohort studies are less biased than case-control studies, some important methodological issues might explain the differences in findings between cohort studies and randomised controlled trials. The diet assessment tools such as the food frequency questionnaire might not precisely assess an individual's long term diet or might not provide sufficient information on fruit and vegetable consumption. Also, and more importantly, the use of vitamin or antioxidant supplements in randomised controlled trials should not be seen as equivalent to the intake of fruit and vegetables in cohort studies, which contain other various micronutrients as well as specific nutritional substances. Beneficial effects of vitamin or antioxidant supplements on cardiovascular disease might be obtained from the combination of various nutrients, not from one or several specific nutrients.

\section{Strengths and weaknesses in relation to other meta-analyses}

Our findings are similar to those of the previous meta-analysis of randomised controlled trials on the association between vitamin or antioxidant supplementation and other outcomes such as mortality and cancer. In 2007, Bjelakovic et al reported that vitamin $\mathrm{A}$, vitamin $\mathrm{E}$, or $\beta$ carotene supplements were 
associated with increased mortality in a meta-analysis of 47 low bias (high quality) trials with 180938 participants, while vitamin $\mathrm{C}$ and selenium were not associated with mortality. ${ }^{78}$ Regarding the negative effect of antioxidant supplements on mortality, they suggested that the elimination of free radicals in the human body through antioxidant supplementation interferes with essential defensive mechanisms such as apoptosis, phagocytosis, and detoxification and might lead to an increased mortality. ${ }^{78}$ Their updated meta-analysis including the recently published trials had similar findings on this issue and suggested that antioxidant supplements should be considered as medicinal products and should undergo sufficient evaluation before they are marketed. ${ }^{79}$ In 2010, Myung et al reported that antioxidant supplements had no primary or secondary preventive effect on cancer and even increased the risk of bladder cancer in a meta-analysis of 22 randomised controlled trials. ${ }^{80}$

Because of these discrepancies in results between preclinical studies and clinical trials, the findings from preclinical studies on the effects or actions of vitamin or antioxidant substances should not be directly applied to humans.

In the meantime, when we performed subgroup meta-analyses by quality (high $v$ low), dose (low $v$ high), and supplements given singly or in combination with other supplements, we found no overall association between vitamin or antioxidant supplements and the risk of major cardiovascular events, while vitamin and antioxidant supplementation were associated with a marginally increased risk of angina pectoris, and low dose vitamin $\mathrm{B}_{6}$ supplementation with a slightly decreased risk of major cardiovascular events. In the subgroup meta-analysis of high quality randomised controlled trials within each category, however, beneficial or harmful effects disappeared. We cannot therefore conclude that vitamin and antioxidant supplements are harmful for angina pectoris or that vitamin $\mathrm{B}_{6}$ supplements are beneficial for major cardiovascular events. Also, even though vitamin $\mathrm{B}_{6}$ supplementation was associated with a decreased risk of cardiovascular mortality in high quality trials, and vitamin E supplementation was associated with a decreased risk of myocardial infarction, those beneficial effects were shown only in trials with supplements provided by the pharmaceutical industry. So we cannot completely exclude the possibility that this might have influenced the respective trial design, results, or interpretations.

We also found that there was a trend toward an increased (not significant) risk of major cardiovascular events for the supplementation group in subgroup meta-analysis of trials with $\geq 10000$ participants, while there was a trend toward a decreased (not significant) risk in subgroup meta-analysis of trials with $<10000$ participants. Given that a larger sample size is more accurate than a smaller size, we cannot exclude that vitamin or antioxidant supplementation might be associated with an increase in the risk of cardiovascular disease. Further large scale trials are needed to confirm this.

\section{Weaknesses of the current meta-analysis}

There are several limitations in the current study. Firstly, we investigated the association only between synthetic vitamin and antioxidant supplements and cardiovascular disease. Thus, our findings could not be directly applied to fruit and vegetables rich in natural vitamins or antioxidants or natural vitamins derived or extracted from plants. Secondly, we were unable to evaluate whether vitamin and antioxidant supplementation would be beneficial against cardiovascular disease for populations who are deficient in vitamins or antioxidants at baseline. Further randomised controlled trials in those populations are needed.
Thirdly, we used the Jadad scale to assess the methodological quality of the trials, which has been criticised because it is subject to the generic problems of scales, has a strong emphasis on reporting rather than conduct, and does not cover concealment of allocation, one of the important biases in randomised controlled trials. ${ }^{81}$ As an alternative, the Cochrane Risk of Bias (RoB) tool has been used to evaluate internal validity of randomised controlled trials since 2008. Hartling et al, however, reported that the inter-rater agreement varied substantially across domains in the Cochrane tool, and it took considerably longer to complete than the Jadad scale. ${ }^{82}$ Further validated tools for the assessment of quality are needed. Finally, we assessed the methodological quality of the trials based only on the data presented in each article. Thus, we might not have assessed the actual performance or biases of each trial.

\section{Meaning of the findings}

In summary, we found no evidence to support the use of vitamin or antioxidant supplements in the prevention of cardiovascular disease. Also, recent meta-analyses have shown that vitamin or antioxidant supplements are associated with increased mortality and have no preventive effect on cancer or were even associated with increases in some types of cancer. Most countries permit the pharmaceutical or food industry to sell these supplements under the name of functional food or medical food, and many people take vitamin or antioxidant supplements in the belief that they improve their health. Based on recent meta-analyses of randomised controlled trials, including the current study, however, governments and regulating agencies for food and drugs should consider vitamin and antioxidant supplements as medicinal products and strictly evaluate their efficacy and safety before marketing.

\section{Unanswered questions and future research}

Further randomised controlled trials are required to determine whether vitamin and antioxidant supplementation would be beneficial against cardiovascular disease for people who are deficient in vitamins or antioxidants at baseline. Regarding the assessment of methodological quality of each trial, further validated tools that could assess the actual performance or biases of each trial should be developed.

Contributors: BC and S-KM were responsible for the initial plan, study design, conducting the study, data interpretation, and manuscript drafting. S-KM was responsible for statistical analysis. S-KM, WJ, and S-WO were responsible for data collection, data extraction, and data interpretation. SMP, B-KK, and B-J P were responsible for data interpretation and manuscript drafting. $\mathrm{BC}$ and $\mathrm{S}-\mathrm{KM}$ are guarantors. Funding: This research received no specific grant from any funding agency in the public, commercial, or not-for-profit sectors.

Competing interests: All authors have completed the ICMJE uniform disclosure form at www.icmje.org/coi_disclosure.pdf (available on request from the corresponding author) and declare: no support from any organisation for the submitted work; no financial relationships with any organisations that might have an interest in the submitted work in the previous three years; no other relationships or activities that could appear to have influenced the submitted work.

Ethical approval: Not required.

Data sharing: No additional data available.

Mendis S, Lindholm LH, Anderson SG, Alwan A, Koju R, Onwubere BJ, et al. Total cardiovascular risk approach to improve efficiency of cardiovascular prevention in resource constrain settings. J Clin Epidemiol 2011;64:1451-62.

2 Dauchet L, Amouyel P, Dallongeville J. Fruits, vegetables and coronary heart disease. Nat Rev Cardiol 2009;6:599-608. 


\section{What is already known on this topic}

Over the past few decades, observational epidemiological studies have reported that intake of fruit and vegetables rich in various vitamins and antioxidants is associated with a reduced risk of cardiovascular disease

Unlike the evidence for the benefits of fruit and vegetables, however, randomised controlled trials have had inconsistent results regarding benefits of vitamin or antioxidant supplements

Even though several meta-analyses of randomised controlled trials have been published, those involved individual vitamin or antioxidant supplements, and there has been no published comprehensive meta-analysis that reviewed this topic all at once in one report

\section{What this study adds}

This large scale meta-analysis of randomised controlled trials suggests that there is no evidence to support the use of vitamin or antioxidant supplements for the primary or secondary prevention of major cardiovascular events

Governments and regulating agencies for food and drug should consider vitamin and antioxidant supplements as medicinal products and strictly evaluate their efficacy and safety before marketing

3 Lock K, Pomerleau J, Causer L, Altmann DR, McKee M. The global burden of disease attributable to low consumption of fruit and vegetables: implications for the global strategy on diet. Bull World Health Organ 2005;83:100-8.

4 Bhupathiraju SN, Tucker KL. Coronary heart disease prevention: nutrients, foods, and dietary patterns. Clin Chim Acta 2011;412:1493-514.

5 Vivekananthan DP, Penn MS, Sapp SK, Hsu A, Topol EJ. Use of antioxidant vitamins for the prevention of cardiovascular disease: meta-analysis of randomised trials. Lancet 2003;361:2017-23.

6 Flores-Mateo G, Navas-Acien A, Pastor-Barriuso R, Guallar E. Selenium and coronary heart disease: a meta-analysis. Am J Clin Nutr 2006;84:762-73.

7 Lee M, Hong KS, Chang SC, Saver JL. Efficacy of homocysteine-lowering therapy with folic acid in stroke prevention: a meta-analysis. Stroke 2010;41:1205-12.

8 Qin X, Huo Y, Langman CB, Hou F, Chen Y, Matossian D, et al. Folic acid therapy and cardiovascular disease in ESRD or advanced chronic kidney disease: a meta-analysis. Clin J Am Soc Nephrol 2011;6:482-8.

9 Jadad AR, Moore RA, Carroll D, Jenkinson C, Reynolds DJ, Gavaghan DJ, et al. Assessing the quality of reports of randomised clinical trials: is blinding necessary? Control Clin Trials 1996;17:1-12.

10 Higgins JP, Thompson SG. Quantifying heterogeneity in a meta-analysis. Stat Med 2002;21:1539-58.

11 Korpela H, Kumpulainen J, Jussila E, Kemilä S, Kääriäinen M, Kääriäinen T, et al. Effect of selenium supplementation after acute myocardial infarction. Res Commun Chem Pathol Pharmacol 1989;65:249-52.

12 Kuklinski B, Weissenbacher E, Fahnrich A. Coenzyme Q10 and antioxidants in acute myocardial infarction. Mol Aspects Med 1994;15suppl:s143-7.

13 Steiner M, Glantz M, Lekos A. Vitamin E plus aspirin compared with aspirin alone in patients with transient ischemic attacks. Am J Clin Nutr 1995;62:1381-4S.

14 Omenn GS, Goodman GE, Thornquist MD, Balmes J, Cullen MR, Glass A, et al. Effects of a combination of beta carotene and vitamin $A$ on lung cancer and cardiovascular disease. N Engl J Med 1996;334:1150-5

15 Stephens NG, Parsons A, Schofield PM, Kelly F, Cheeseman K, Mitchinson MJ. Randomised controlled trial of vitamin $\mathrm{E}$ in patients with coronary disease: Cambridge Heart Antioxidant Study (CHAOS). Lancet 1996;347:781-6.

16 Mark SD, Wang W, Fraumeni JF Jr, Li JY, Taylor PR, Wang GQ, et al. Lowered risks of hypertension and cerebrovascular disease after vitamin/mineral supplementation: the Linxian Nutrition Intervention Trial. Am J Epidemiol 1996;143:658-64.

17 Hennekens CH, Buring JE, Manson JE, Stampfer M, Rosner B, Cook NR, et al. Lack of effect of long-term supplementation with beta carotene on the incidence of malignant neoplasms and cardiovascular disease. N Engl J Med 1996;334:1145-9.

18 Greenberg ER, Baron JA, Karagas MR, Stukel TA, Nierenberg DW, Stevens MM, et al. Mortality associated with low plasma concentration of beta carotene and the effect of ora supplementation. JAMA 1996;275:699-703.

19 Rapola JM, Virtamo J, Ripatti S, Huttenen JK, Albanes D, Taylor PR, et al. Randomised trial of alpha-tocopherol and beta-carotene supplements on incidence of major coronary events in men with previous myocardial infarction. Lancet 1997;349:1715-20.

20 Virtamo J, Rapola JM, Ripatti S, Heinonen OP, Taylor PR, Albanes D, et al. Effect of vitamin $\mathrm{E}$ and beta carotene on the incidence of primary nonfatal myocardial infarction and fatal coronary heart disease. Arch Intern Med 1998;158:668-75.

21 GISSI-Prevenzione Investigators (Gruppo Italiano per lo Studio della Sopravvivenza nell'Infarto miocardico). Dietary supplementation with $n-3$ polyunsaturated fatty acids and vitamin E after myocardial infarction: results of the GISSI-Prevenzione trial. Lancet 1999;354:447-55.

22 Komulainen M, Kröger H, Tuppurainen MT, Heikkinen AM, Alhava E, Honkanen R, et al. Prevention of femoral and lumbar bone loss with hormone replacement therapy and vitamin D3 in early postmenopausal women: a population-based 5-year randomised trial. $J$ Clin Endocrinol Metab 1999;84:546-52.

23 Green A, Williams G, Neale R, Hart V, Leslie D, Parsons P, et al. Daily sunscreen application and betacarotene supplementation in prevention of basal-cell and squamous-cell carcinomas of the skin: a randomised controlled trial. Lancet 1999:354:723-9.

24 Yusuf S, Dagenais G, Pogue J, Bosch J, Sleight P. Vitamin E supplementation and cardiovascular events in high-risk patients. The Heart Outcomes Prevention Evaluation Study Investigators. N Engl J Med 2000;342:154-60.

25 Boaz M, Smetana S, Weinstein T, Matas Z, Gafter U, laina A, et al. Secondary prevention with antioxidants of cardiovascular disease in endstage renal disease (SPACE): randomised placebo-controlled trial. Lancet 2000;356:1213-8.

26 Brown BG, Zhao XQ, Chait A, Fisher LD, Cheung MC, Morse JS, et al. Simvastatin and niacin, antioxidant vitamins, or the combination for the prevention of coronary disease. $N$ Engl J Med 2001;345:1583-92.

27 De Gaetano G; Collaborative Group of the Primary Prevention Project. Low-dose aspirin and vitamin $\mathrm{E}$ in people at cardiovascular risk: a randomised trial in general practice. Lancet 2001;357:89-95.
28 You WC, Chang YS, Heinrich J, Ma JL, Liu WD, Zhang L, et al. An intervention trial to inhibit the progression of precancerous gastric lesions: compliance, serum micronutrients and S-allyl cysteine levels, and toxicity. Eur J Cancer Prev 2001;10:257-63.

29 Rafiee $\mathrm{P}$, Shi Y, Kong X, Pritchard KA Jr, Tweddell JS, Litwin SB, et al. Activation of protein kinases in chronically hypoxic infant human and rabbit hearts: role in cardioprotection. Circulation 2002;106:239-45.

30 Heart Protection Study Collaborative Group. MRC/BHF Heart Protection Study of antioxidant vitamin supplementation in 20,536 high-risk individuals: a randomised placebo-controlled trial. Lancet 2002;360:23-33.

31 Schnyder G, Roffi M, Flammer Y, Pin R, Hess OM. Effect of homocysteine-lowering therapy with folic acid, vitamin B12, and vitamin B6 on clinical outcome after percutaneous coronary intervention: the Swiss Heart study: a randomised controlled trial. JAMA 2002;288:973-9.

32 Waters DD, Alderman EL, Hsia J, Howard BV, Cobb FR, Rogers WJ, et al. Effects of hormone replacement therapy and antioxidant vitamin supplements on coronary atherosclerosis in postmenopausal women: a randomised controlled trial. JAMA 2002;288:2432-40.

33 Liem A, Reynierse-Buitenwerf GH, Zwinderman AH, Jukema JW, van Veldhuisen DJ. Secondary prevention with folic acid: effects on clinical outcomes. J Am Coll Cardiol 2003;41:2105-13.

34 Righetti M, Ferrario GM, Milani S, Serbelloni P, La Rosa L, Uccellini M, et al. Effects of folic acid treatment on homocysteine levels and vascular disease in hemodialysis patients. Med Sci Monit 2003:9:PI19-24.

35 Trivedi DP, Doll R, Khaw KT. Effect of four monthly oral vitamin D3 (cholecalciferol) supplementation on fractures and mortality in men and women living in the community: randomised double blind controlled trial. BMJ 2003;326:469.

36 Lange H, Suryapranata H, De Luca G, Börner C, Dille J, Kallmayer K, et al. Folate therapy and in-stent restenosis after coronary stenting. N Engl J Med 2004;350:2673-81.

37 Hercberg S, Galan P, Preziosi P, Bertrais S, Mennen L, Malvy D, et al. The SU.VI.MAX Study: a randomised, placebo-controlled trial of the health effects of antioxidant vitamins and minerals. Arch Intern Med 2004;164:2335-42.

38 Toole JF, Malinow MR, Chambless LE, Spence JD, Pettigrew LC, Howard VJ, et al. Lowering homocysteine in patients with ischemic stroke to prevent recurrent stroke, myocardial infarction, and death: the Vitamin Intervention for Stroke Prevention (VISP) randomised controlled trial. JAMA 2004;291:565-75.

39 Wrone EM, Hornberger JM, Zehnder JL, McCann LM, Coplon NS, Fortmann SP. Randomised trial of folic acid for prevention of cardiovascular events in end-stage renal disease. J Am Soc Nephrol 2004;15:420-6.

40 Brazier M, Grados F, Kamel S, Mathieu M, Morel A, Maamer M, et al. Clinical and laboratory safety of one year's use of a combination calcium + vitamin D tablet in ambulatory elderly women with vitamin $\mathrm{D}$ insufficiency: results of a multicenter, randomised, double-blind, placebo-controlled study. Clin Ther 2005;27:1885-93.

41 Lee IM, Cook NR, Gaziano JM, Gordon D, Ridker PM, Manson JE, et al. Vitamin E in the primary prevention of cardiovascular disease and cancer: the Women's Health Study: a randomised controlled trial. JAMA 2005;294:56-65.

42 Zoungas S, McGrath BP, Branley P, Kerr PG, Muske C, Wolfe R, et al. Cardiovascular morbidity and mortality in the atherosclerosis and folic acid supplementation trial (ASFAST) in chronic renal failure: a multicenter, randomised, controlled trial. J Am Coll Cardiol 2006;47:1108-16.

43 Lonn E, Yusuf S, Arnold MJ, Sheridan P, Pogue J, Micks M, et al. Homocysteine lowering with folic acid and B vitamins in vascular disease. N Engl J Med 2006;354:1567-77.

44 Bønaa KH, Njølstad I, Ueland PM, Schirmer H, Tverdal A, Steigen T, et al. Homocysteine lowering and cardiovascular events after acute myocardial infarction. $N$ Engl J Med 2006:354:1578-88

45 Stranges S, Marshall JR, Trevisan M, Natarajan R, Donahue RP, Combs GF, et al. Effects of selenium supplementation on cardiovascular disease incidence and mortality: secondary analyses in a randomised clinical trial. Am J Epidemiol 2006;163:694-9.

46 Jamison RL, Hartigan P, Kaufman JS, Goldfarb DS, Warren SR, Guarino PD, et al. Effect of homocysteine lowering on mortality and vascular disease in advanced chronic kidney disease and end-stage renal disease: a randomised controlled trial. JAMA 2007;298:1163-70.

47 Hsia J, Heiss G, Ren H, Allison M, Dolan NC, Greenland P, et al. Calcium/vitamin D supplementation and cardiovascular events. Circulation 2007;115:846-54.

48 Berggren M, Stenvall M, Olofsson B, Gustafson Y. Evaluation of a fall-prevention program in older people after femoral neck fracture: a one-year follow-up. Osteoporos Int 2008;19:801-9.

49 Milman U, Blum S, Shapira C, Aronson D, Miller-Lotan R, Anbinder Y, et al. Vitamin E supplementation reduces cardiovascular events in a subgroup of middle-aged individuals with both type 2 diabetes mellitus and the haptoglobin 2-2 genotype: a prospective double-blinded clinical trial. Arterioscler Thromb Vasc Biol 2008;28:341-7.

50 Prince RL, Austin N, Devine A, Dick IM, Bruce D, Zhu K. Effects of ergocalciferol added to calcium on the risk of falls in elderly high-risk women. Arch Intern Med 2008;168:103-8. 
51 Albert CM, Cook NR, Gaziano JM, Zaharris E, MacFadyen J, Danielson E, et al. Effect of folic acid and $\mathrm{B}$ vitamins on risk of cardiovascular events and total mortality among women at high risk for cardiovascular disease: a randomised trial. JAMA 2008;299:2027-36.

52 Ebbing M, Bleie $\varnothing$, Ueland PM, Nordrehaug JE, Nilsen DW, Vollset SE, et al. Mortality and cardiovascular events in patients treated with homocysteine-lowering $B$ vitamins after coronary angiography: a randomised controlled trial. JAMA 2008;300:795-804.

53 Hodis HN, Mack WJ, Dustin L, Mahrer PR, Azen SP, Detrano R, et al. High-dose B vitamin supplementation and progression of subclinical atherosclerosis: a randomised controlled trial. Stroke 2009;40:730-6

54 House AA, Eliasziw M, Cattran DC, Churchill DN, Oliver MJ, Fine A, et al. Effect of $\mathrm{B}$-vitamin therapy on progression of diabetic nephropathy: a randomised controlled trial. JAMA 2010;303:1603-9.

55 Heinz J, Kropf S, Domröse U, Westphal S, Borucki K, Luley C, et al. B vitamins and the risk of total mortality and cardiovascular disease in end-stage renal disease: results of a randomised controlled trial. Circulation 2010;121:1432-8.

56 Armitage JM, Bowman L, Clarke RJ, Wallendszus K, Bulbulia R, Rahimi K, et al. Effects of homocysteine-lowering with folic acid plus vitamin B12 vs placebo on mortality and major morbidity in myocardial infarction survivors: a randomised trial. JAMA 2010;303:2486-94

57 Galan P, Kesse-Guyot E, Czernichow S, Briancon S, Blacher J, Hercberg S. Effects of $B$ vitamins and omega 3 fatty acids on cardiovascular diseases: a randomised placebo controlled trial. BMJ 2010;341:c6273

58 VITATOPS Trial Study Group. B vitamins in patients with recent transient ischaemic attack or stroke in the VITAmins TO Prevent Stroke (VITATOPS) trial: a randomised, double-blind, parallel, placebo-controlled trial. Lancet Neurol 2010;9:855-65.

59 Bostom AG, Carpenter MA, Kusek JW, Levey AS, Hunsicker L, Pfeffer MA, et al Homocysteine-lowering and cardiovascular disease outcomes in kidney transplant recipients: primary results from the folic acid for vascular outcome reduction in transplantation trial. Circulation 2011;123:1763-70

60 Sesso HD, Christen WG, Bubes V, Smith JP, MacFadyen J, Schavartz M, et al. Multivitamins in the prevention of cardiovascular disease in men: the Physicians' Health Study II randomised controlled trial. JAMA 2012;308:1751-60.

61 Clarke R, Halsey J, Lewington S, Lonn E, Armitage J, Manson JE, et al. Effects of lowering homocysteine levels with B vitamins on cardiovascular disease, cancer, and cause-specific mortality: meta-analysis of 8 randomised trials involving 37485 individuals. Arch Intern Med 2010;170:1622-31.

62 Mei W, Rong Y, Jinming L, Yongjun L, Hui Z. Effect of homocysteine interventions on the risk of cardiocerebrovascular events: a meta-analysis of randomised controlled trials. Int Clin Pract 2010;64:208-15

63 Elamin MB, Abu Elnour NO, Elamin KB, Fatourechi MM, Alkatib AA, Almandoz JP, et al. Vitamin $D$ and cardiovascular outcomes: a systematic review and meta-analysis. J Clin Endocrinol Metab 2011;96:1931-42.

64 Eidelman RS, Hollar D, Hebert PR, Lamas GA, Hennekens CH. Randomised trials of vitamin $\mathrm{E}$ in the treatment and prevention of cardiovascular disease. Arch Intern Med 2004;164:1552-6

65 Shekelle PG, Morton SC, Jungvig LK, Udani J, Spar M, Tu W, et al. Effect of supplemental vitamin $\mathrm{E}$ for the prevention and treatment of cardiovascular disease. J Gen Intern Med 2004;19:380-9.

66 Zhou YH, Tang JY, Wu MJ, Lu J, Wei X, Qin YY, et al. Effect of folic acid supplementation on cardiovascular outcomes: a systematic review and meta-analysis. PLoS One 2011:6:e25142.

67 Parker RA, Sabrah T, Cap M, Gill BT. Relation of vascular oxidative stress, alpha-tocopherol, and hypercholesterolemia to early atherosclerosis in hamsters. Arterioscler Thromb Vasc Biol 1995;15:349-58.
68 Pratico D, Tangirala RK, Rader DJ, Rokach J, FitzGerald GA. Vitamin E suppresses isoprostane generation in vivo and reduces atherosclerosis in ApoE-deficient mice. Nat Med 1998:4:1189-92.

69 Crawford RS, Kirk EA, Rosenfeld ME, LeBoeuf RC, Chait A. Dietary antioxidants inhibit development of fatty streak lesions in the LDL receptor-deficient mouse. Arterioscler Thromb Vasc Biol 1998;18:1506-13.

70 Diaz MN, Frei B, Vita JA, Keaney JF Jr. Antioxidants and atherosclerotic heart disease. N Engl J Med 1997;337:408-16.

71 Ricciarelli R, Zingg JM, Azzi A. Vitamin E reduces the uptake of oxidized LDL by inhibiting CD36 scavenger receptor expression in cultured aortic smooth muscle cells. Circulation 2000;102:82-7

72 Ulrich-Merzenich G, Metzner C, Schiermeyer B, Vetter H. Vitamin C and vitamin E antagonistically modulate human vascular endothelial and smooth muscle cell DNA synthesis and proliferation. Eur $J$ Nutr 2002:41:27-34

73 Farbstein D, Kozak-Blickstein A, Levy AP. Antioxidant vitamins and their use in preventing cardiovascular disease. Molecules 2010;15:8098-110.

74 Quinn MT, Parthasarathy S, Fong LG, Steinberg D. Oxidatively modified low density lipoproteins: a potential role in recruitment and retention of monocyte/macrophages during atherogenesis. Proc Natl Acad Sci U S A 1987;84:2995-8.

75 Henriksen T, Mahoney EM, Steinberg D. Enhanced macrophage degradation of low density lipoprotein previously incubated with cultured endothelial cells: recognition by receptors for acetylated low density lipoproteins. Proc Natl Acad Sci U S A 1981;78:6499-503.

76 Schwartz CJ, Valente AJ, Sprague EA, Kelley JL, Nerem RM. The pathogenesis of atherosclerosis: an overview. Clin Cardiol 1991;14:11-16.

77 Aguirre R, May JM. Inflammation in the vascular bed: importance of vitamin C. Pharmacol Ther 2008:119:96-103.

78 Bjelakovic G, Nikolova D, Gluud LL, Simonetti RG, Gluud C. Mortality in randomised trials of antioxidant supplements for primary and secondary prevention: systematic review and meta-analysis. JAMA 2007;297:842-57.

79 Bjelakovic G, Nikolova D, Gluud LL, Simonetti RG, Gluud C. Antioxidant supplements for prevention of mortality in healthy participants and patients with various diseases. Cochrane Database Syst Rev 2012;3:CD007176.

80 Myung SK, Kim Y, Ju W, Choi HJ, Bae WK. Effects of antioxidant supplements on cance prevention: meta-analysis of randomised controlled trials. Ann Oncol 2010;21:166-79.

81 Higgins JPT, Green S, eds. Cochrane handbook for systematic reviews of interventions. Version 5.0.0, February 2008. www.cochrane-handbook.org.

82 Hartling L, Ospina M, Liang Y, Dryden DM, Hooton N, Krebs Seida J, et al. Risk of bias versus quality assessment of randomised controlled trials: cross sectional study. $B M J$ 2009;339:b4012.

83 Sesso HD, Buring JE, Christen WG, Kurth T, Belanger C, MacFadyen J, et al. Vitamins $E$ and $C$ in the prevention of cardiovascular disease in men: the Physicians' Health Study II randomised controlled trial. JAMA 2008;300:2123-33.

\section{Accepted: 19 December 2012}

\section{Cite this as: BMJ 2013;346:f10}

This is an open-access article distributed under the terms of the Creative Commons Attribution Non-commercial License, which permits use, distribution, and reproduction in any medium, provided the original work is properly cited, the use is non commercial and is otherwise in compliance with the license. See: $\mathrm{http}: / /$ creativecommons.org/licenses/bync/2.0/ and http://creativecommons.org/licenses/by-nc/2.0/legalcode. 


\section{Tables}

\section{Table 1 | Methodological quality, based on Jadad scale, of $4 \mathbf{7}^{*}$ included trials on efficacy of vitamin and antioxidant supplements in prevention} of cardiovascular diseases

Description of

Randomisation randomisation methods Double blind Used identical placebo Follow-up reporting Total score

Steiner, $1995^{13}$

Omenn, $1996(\text { CARET) })^{14}$

Stephens, 1996 (CHAOS) $^{15}$

Mark, 1996 (LNIT) ${ }^{16}$

Hennekens, $1996(\mathrm{PHS})^{17}$

Greenberg, $1996(\mathrm{SCP})^{18}$

Rapola, 1997 (ATBC) $)^{19}$

Virtamo, 1998 (ATBC) $)^{20}$

GISSI, $1999^{21}$

$1 \quad 0$

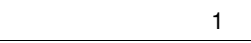

Komulainen, $1999(\mathrm{KOS})^{22} \quad 1$

Green, 1999 (NSCP) ${ }^{23}$

Yusuf, 2000 (HOPE) $)^{24}$

Boaz, 2000 (SPACE) $)^{25}$

Brown, 2001 (HATS) ${ }^{26}$

De Gaetano, 2001 (PPP) ${ }^{27}$

You, $2001^{28}$

HPS, 2002 $2^{30}$

Schnyder, $2002(\mathrm{SHS})^{3}$

Waters, 2002 (WAVE) $)^{32}$

Liem, 2003 (Goes) ${ }^{33}$

Righetti, $2003^{34}$

Trivedi, $2003^{35}$

Lange, $2004^{36}$

Hercberg, 2004 (SU.VI.MAX) ${ }^{37}$

Toole, 2004 (VISP) $)^{38}$

Wrone, 2004 ${ }^{39}$

Brazier, 2005 ${ }^{40}$

Lee, 2005 (WHS)

Zoungas, 2006 (ASFAST) ${ }^{42}$

Lonn, 2006 (HOPE-2) ${ }^{43}$

Bønaa, 2006 (NORVIT) $^{44}$

Stranges, $2006(\mathrm{NPC})^{45}$

Jamison, 2007 (HOST) ${ }^{46}$

Hsia, 2007 (WHI) ${ }^{47}$

Berggren, $2008^{48}$

Milman, 2008 (ICARE) ${ }^{49}$

Prince, $2008^{50}$

Albert, 2008 (WAFACS) ${ }^{5}$

1

1
1
1

1

$\begin{array}{llll}1 & 1 & 1 & 4 \\ 1 & 1 & 1 & 5 \\ 1 & 1 & 1 & 5\end{array}$

Ebbing, 2008 (WENBIT) ${ }^{52}$

Hodis, 2009 (BVAIT) ${ }^{53}$

House, 2010 (DIVINe) $)^{54}$

$\begin{array}{ll}1 & 0 \\ 1 & 1\end{array}$

$\begin{array}{lll}1 & 1 \\ 1 & 1\end{array}$

Heinz $2010^{55}$

Armitage, $2010(\text { SEARCH) })^{56}$

Galan, 2010 (SU.FOL.OM3)

$\begin{array}{ll}1 & 1 \\ 1 & 1 \\ 1 & 1\end{array}$

$\begin{array}{ll}1 & 1 \\ 1 & 1\end{array}$

1


Table 1 (continued)

\begin{tabular}{lccccccc} 
& Randomisation & $\begin{array}{c}\text { Description of } \\
\text { randomisation methods }\end{array}$ & Double blind & Used identical placebo Follow-up reporting & Total score \\
VITATOPS 2010 & 1 & 1 & 1 & 1 & 1 & 1 & 5 \\
\hline Bostom, 2011 (FAVORIT) & 1 & 1 & 1 & 1 & 1 & 1 & 5 \\
\hline Sesso, 2012 (PHS2) & 1 & & 1 & 1 & 1 & 1 & 5 \\
\hline
\end{tabular}

${ }^{*}$ We were unable to retrieve full text from three trials: Korpela et al, $1989,{ }^{11}$ Kuklinski et al, 1994, ${ }^{12}$ and Rafiee et al, $2002 .{ }^{29}$ 
Table 2| Efficacy of vitamin and antioxidant supplements in the prevention of the major cardiovascular events in subgroup meta-analysis by type of prevention and type of supplement

\begin{tabular}{|c|c|c|c|c|}
\hline Factor & No of trials & Relative risk (95\% Cl) & Heterogeneity $I^{2}(\%)$ & Model \\
\hline All & 50 & 1.00 (0.98 to 1.02$)$ & 42 & Fixed effects \\
\hline \multicolumn{5}{|l|}{ Prevention: } \\
\hline Primary & 30 & 1.01 (0.98 to 1.03$)$ & 42 & Fixed effects \\
\hline Secondary & 20 & 1.00 (0.97 to 1.03$)$ & 44 & Fixed effects \\
\hline \multicolumn{5}{|l|}{ Type of supplement: } \\
\hline Vitamins only & 39 & 0.99 (0.97 to 1.01$)$ & 44 & Fixed effects \\
\hline Low quality trials & 17 & 0.99 (0.96 to 1.02$)$ & 32 & Fixed effects \\
\hline High quality trials & 22 & 0.99 (0.94 to 1.05$)$ & 53 & Random effects \\
\hline Antioxidants only & 22 & 0.98 (0.96 to 1.02$)$ & 41 & Fixed effects \\
\hline Low quality trials & 11 & 0.99 (0.96 to 1.03$)$ & 25 & Fixed effects \\
\hline High quality trial & 9 & 0.97 (0.91 to 1.02$)$ & 49 & Fixed effects \\
\hline Vitamin A & 2 & 0.98 (0.45 to 2.16$)$ & 87 & Random effects \\
\hline Low dose (10 000 IU/day) & 1 & 0.63 (0.37 to 1.07$)$ & NA & NA \\
\hline High dose (25 000 IU/day) & 1 & $1.41(1.15 \text { to } 1.73)^{*}$ & NA & NA \\
\hline Vitamin $\mathrm{B}_{6}$ & 16 & 0.96 (0.92 to 1.01$)$ & 33 & Fixed effects \\
\hline Low dose (3-25 mg/day) & 8 & $0.92(0.85 \text { to } 0.99)^{*}$ & 35 & Fixed effects \\
\hline Low quality trials & 3 & $0.76(0.61 \text { to } 0.94)^{*}$ & 0 & Fixed effects \\
\hline High quality trials & 5 & 0.94 (0.87 to 1.02 ) & 39 & Fixed effects \\
\hline High dose (40-100 mg/day) & 8 & 0.99 (0.94 to 1.05$)$ & 22 & Fixed effects \\
\hline Vitamin $\mathrm{B}_{12}$ & 17 & 0.99 (0.95 to 1.02$)$ & 37 & Fixed effects \\
\hline Low dose $(6 \mu \mathrm{g}-0.5 \mathrm{mg} /$ day $)$ & 11 & 0.96 (0.90 to 1.02$)$ & 34 & Fixed effects \\
\hline High dose (1-2 mg/day) & 6 & 1.00 (0.96 to 1.05$)$ & 43 & Fixed effects \\
\hline Folic acid & 21 & 0.99 (0.95 to 1.02$)$ & 35 & Fixed effects \\
\hline Low dose $(500 \mu \mathrm{g}-5 \mathrm{mg} /$ day $)$ & 17 & 0.99 (0.96 to 1.03$)$ & 39 & Fixed effects \\
\hline High dose (10-40 mg/day) & 4 & 0.89 (0.78 to 1.03 ) & 0 & Fixed effects \\
\hline Vitamin C† & 7 & 0.99 (0.94 to 1.04$)$ & 16 & Fixed effects \\
\hline Low dose $(120-250 \mathrm{mg} /$ day $)$ & 3 & 0.99 (0.94 to 1.04$)$ & 31 & Fixed effects \\
\hline High dose (500-1000 mg/day) & 4 & 0.98 (0.94 to 1.12$)$ & 28 & Fixed effects \\
\hline Vitamin D & 7 & 1.02 (0.98 to 1.07 ) & 23 & Fixed effects \\
\hline Low dose $(120-250 \mathrm{mg} /$ day $)$ & 2 & 1.05 (0.99 to 1.12$)$ & 0 & Fixed effects \\
\hline High dose (500-1000 mg/day) & 5 & 0.94 (0.86 to 1.03 ) & 0 & Fixed effects \\
\hline Vitamin $\mathrm{E} \dagger$ & 17 & 0.97 (0.94 to 1.01$)$ & 44 & Fixed effects \\
\hline Low dose (60 IU-250 mg/day) & 13 & 0.96 (0.92 to 1.01$)$ & 35 & Fixed effects \\
\hline High dose $(500-600 \mathrm{mg} /$ day $)$ & 4 & 0.84 (0.52 to 1.35$)$ & 69 & Random effects \\
\hline$\beta$ carotene & 11 & 1.04 (0.96 to 1.12 ) & 55 & Random effects \\
\hline Low dose $(6-25 \mathrm{mg} /$ day $)$ & 6 & 0.99 (0.95 to 1.03$)$ & 7 & Fixed effects \\
\hline High dose (30-50 mg/day) & 5 & 1.14 (0.96 to 1.35$)$ & 69 & Random effects \\
\hline Selenium & 7 & 0.91 (0.77 to 1.06 ) & 47 & Fixed effects \\
\hline Low dose $(50-100 \mu \mathrm{g} /$ day $)$ & 5 & 0.85 (0.70 to 1.04$)$ & 44 & Fixed effects \\
\hline High dose $(122-200 \mu \mathrm{g} /$ day $)$ & 2 & $0.57(0.10$ to 3.16$)$ & 67 & Fixed effects \\
\hline
\end{tabular}

$\mathrm{NA}=$ not applicable.

${ }^{*} \mathrm{P} \leq 0.05$.

†For subgroup meta-analysis of vitamin C and vitamin E, we used data from 2008 PHS2 article ${ }^{83}$ because data were not available in 2012 PHS article. 


\begin{tabular}{|c|c|c|c|c|}
\hline & No of trials & Relative risk $(95 \% \mathrm{Cl})$ & Heterogeneity $I^{2}(\%)$ & Model \\
\hline Cardiovascular death & 32 & $1.01(0.97$ to 1.05$)$ & 41 & Fixed effects \\
\hline Vitamin A & 2 & $0.98(0.45$ to 2.16$)$ & 87 & Random effects \\
\hline Vitamin $B_{6}$ & 8 & $0.91(0.83 \text { to } 0.99)^{*}$ & 0 & Fixed effects \\
\hline Low quality trials & 4 & 0.93 (0.75 to 1.14$)$ & 12 & Fixed effects \\
\hline High quality trials & 4 & $0.90(0.82 \text { to } 0.99)^{*}$ & 0 & Fixed effects \\
\hline Not supplied by pharmaceutical industry & 2 & $0.96(0.84$ to 1.10$)$ & 0 & Fixed effects \\
\hline Supplied by pharmaceutical industry & 2 & $0.85(0.75 \text { to } 0.97)^{\star}$ & 0 & Fixed effects \\
\hline Not supplied by pharmaceutical industry & 3 & $0.96(0.83$ to 1.10$)$ & 0 & Fixed effects \\
\hline Supplied by pharmaceutical industry & 5 & $0.88(0.79 \text { to } 0.98)^{*}$ & 0 & Fixed effects \\
\hline Vitamin $B_{12}$ & 9 & $0.96(0.90$ to 1.03$)$ & 27 & Fixed effects \\
\hline Folic acid & 11 & 0.96 (0.89 to 1.03$)$ & 11 & Fixed effects \\
\hline Vitamin $\mathrm{C} \dagger$ & 6 & 1.03 (0.95 to 1.12$)$ & 27 & Fixed effects \\
\hline Vitamin D & 3 & 0.90 (0.76 to 1.07$)$ & 27 & Fixed effects \\
\hline Vitamin E† & 15 & 0.98 (0.92 to 1.04$)$ & 37 & Fixed effects \\
\hline$\beta$ carotene & 10 & $1.10(0.96$ to 1.27$)$ & 61 & Random effects \\
\hline Selenium & 15 & 0.98 (0.92 to 1.04$)$ & 37 & Fixed effects \\
\hline Vitamin & 2 & 0.98 (0.45 to 2.16$)$ & 87 & Random effects \\
\hline Angina & 10 & $1.04(1.00 \text { to } 1.08)^{\star}$ & 36 & Fixed effects \\
\hline Low quality trials & 6 & $1.05(1.00 \text { to } 1.09)^{\star}$ & 25 & Fixed effects \\
\hline High quality trials & 4 & 1.01 (0.86 to 1.18$)$ & 57 & Random effects \\
\hline Vitamin $\mathrm{B}_{6}$ & 4 & $0.93(0.72$ to 1.20$)$ & 77 & Random effects \\
\hline Vitamin $B_{12}$ & 4 & $0.93(0.72$ to 1.20$)$ & 77 & Random effects \\
\hline Folic acid & 4 & $0.93(0.72$ to 1.20$)$ & 77 & Random effects \\
\hline Vitamin C† & 2 & $0.94(0.85$ to 1.03$)$ & 0 & Fixed effects \\
\hline Vitamin D & 1 & 1.07 (0.93 to 1.23$)$ & NA & NA \\
\hline Vitamin E† & 3 & 1.15 (0.99 to 1.33 ) & 0 & Fixed effects \\
\hline Myocardial infarction & 34 & 1.00 (0.96 to 1.03$)$ & 0 & Fixed effects \\
\hline Vitamin $\mathrm{B}_{6}$ & 13 & 0.99 (0.91 to 1.07$)$ & 11 & Fixed effects \\
\hline Vitamin $B_{12}$ & 14 & $0.99(0.93$ to 1.06$)$ & 4 & Fixed effects \\
\hline Folic acid & 15 & 0.99 (0.93 to 1.06$)$ & 0 & Fixed effects \\
\hline Vitamin $\mathrm{C} \dagger$ & 4 & $0.96(0.87$ to 1.07$)$ & 0 & Fixed effects \\
\hline Vitamin D & 2 & $1.06(0.92$ to 1.21$)$ & 0 & Fixed effects \\
\hline Vitamin E† & 12 & $0.77(0.65 \text { to } 0.91)^{*}$ & 76 & Random effects \\
\hline Low quality trials & 5 & 0.76 (0.57 to 1.01$)$ & 81 & Random effects \\
\hline High quality trials & 7 & $0.75(0.58 \text { to } 0.97)^{\star}$ & 75 & Random effects \\
\hline Not supplied by pharmaceutical industry & 4 & 0.79 (0.53 to 1.17$)$ & 62 & Random effects \\
\hline Supplied by pharmaceutical industry & 3 & $0.67(0.42 \text { to } 1.07)^{\star}$ & 86 & Random effects \\
\hline Primary prevention & 7 & $0.72(0.54 \text { to } 0.95)^{\star}$ & 76 & Random effects \\
\hline Not supplied by pharmaceutical industry & 3 & $0.79(0.42$ to 1.50$)$ & 55 & Random effects \\
\hline Supplied by pharmaceutical industry & 4 & $0.63(0.42 \text { to } 0.97)^{*}$ & 82 & Random effects \\
\hline Secondary prevention & 5 & 0.79 (0.61 to 1.02$)$ & 80 & Random effects \\
\hline Not supplied by pharmaceutical industry & 4 & $0.79(0.53$ to 1.17$)$ & 62 & Random effects \\
\hline Supplied by pharmaceutical industry & 8 & $0.73(0.59 \text { to } 0.92)^{*}$ & 82 & Random effects \\
\hline$\beta$ carotene & 4 & 0.95 (0.80 to 1.14$)$ & 52 & Random effects \\
\hline Selenium & 3 & 0.87 (0.59 to 1.28$)$ & 0 & Fixed effects \\
\hline Fatal myocardial infarction & 9 & 1.02 (0.92 to 1.12$)$ & 43 & Fixed effects \\
\hline Vitamin $B_{6}$ & 1 & $1.00(0.75$ to 1.33$)$ & NA & NA \\
\hline Vitamin $B_{12}$ & 1 & $1.00(0.75$ to 1.33$)$ & NA & NA \\
\hline
\end{tabular}


Table 3 (continued)

\begin{tabular}{|c|c|c|c|c|}
\hline & No of trials & Relative risk $(95 \% \mathrm{Cl})$ & Heterogeneity I' (\%) & Model \\
\hline Folic acid & 1 & $1.00(0.75$ to 1.33$)$ & NA & NA \\
\hline Vitamin E† & 3 & 0.57 (0.32 to 1.03$)$ & 0 & Fixed effects \\
\hline$\beta$ carotene & 1 & $1.05(0.95$ to 1.17$)$ & NA & NA \\
\hline Selenium & 1 & $1.12(0.43$ to 2.87$)$ & NA & NA \\
\hline Non-fatal myocardial infarction & 13 & $0.83(0.66$ to 1.04$)$ & 89 & Random effects \\
\hline Vitamin $\mathrm{B}_{6}$ & 3 & $1.08(0.90$ to 1.30$)$ & 22 & Fixed effects \\
\hline Vitamin $\mathrm{B}_{12}$ & 4 & 1.03 (0.93 to 1.14$)$ & 1 & Fixed effects \\
\hline Folic acid & 4 & $1.03(0.93$ to 1.14$)$ & 1 & Fixed effects \\
\hline Vitamin $\mathrm{C} \dagger$ & 4 & 0.85 (0.70 to 1.04$)$ & 0 & Random effects \\
\hline Vitamin E† & 9 & $0.57(0.32$ to 1.03$)$ & 0 & Fixed effects \\
\hline$\beta$ carotene & 4 & 0.95 (0.80 to 1.14$)$ & 52 & Random effects \\
\hline Selenium & 3 & $0.82(0.53$ to 1.27$)$ & 0 & Fixed effects \\
\hline Stroke & 32 & 0.97 (0.93 to 1.02$)$ & 0 & Fixed effects \\
\hline Vitamin $\mathrm{B}_{6}$ & 12 & $0.93(0.85$ to 1.01$)$ & 13 & Fixed effects \\
\hline Vitamin $\mathrm{B}_{12}$ & 5 & $0.91(0.80$ to 1.03$)$ & 8 & Fixed effects \\
\hline Folic acid & 7 & 0.90 (0.79 to 1.01$)$ & 19 & Fixed effects \\
\hline Vitamin $\mathrm{C} \dagger$ & 4 & 0.98 (0.88 to 1.09$)$ & 0 & Fixed effects \\
\hline Vitamin D & 5 & 1.00 (0.88 to 1.13$)$ & 6 & Fixed effects \\
\hline Vitamin E† & 12 & 1.00 (0.93 to 1.09$)$ & 20 & Fixed effects \\
\hline$\beta$ carotene & 2 & $0.98(0.89$ to 1.07$)$ & 0 & Fixed effects \\
\hline Selenium & 1 & 1.09 (0.68 to 1.72$)$ & NA & NA \\
\hline Transient ischaemic attack & 5 & $1.12(0.97$ to 1.30$)$ & 0 & Fixed effects \\
\hline Vitamin B6 & 2 & $1.12(0.88$ to 1.42$)$ & 0 & Fixed effects \\
\hline Vitamin $\mathrm{B}_{12}$ & 2 & $1.12(0.88$ to 1.42$)$ & 0 & Fixed effects \\
\hline Folic acid & 2 & 1.12 (0.88 to 1.42$)$ & 0 & Fixed effects \\
\hline Vitamin D & 1 & $1.12(0.96$ to 1.42$)$ & NA & NA \\
\hline Vitamin E† & 2 & 0.93 (0.59 to 1.47$)$ & 0 & Fixed effects \\
\hline
\end{tabular}

$\mathrm{NA}=$ not applicable.

${ }^{*} \mathrm{P} \leq 0.05$.

†For subgroup meta-analysis of vitamin C and vitamin E, we used data from 2008 PHS2 article ${ }^{83}$ because data were not available in 2012 PHS article. 


\begin{tabular}{|c|c|c|c|c|}
\hline Factor & No of trials & Relative risk $(95 \% \mathrm{Cl})$ & Heterogeneity, $I^{2}(\%)$ & Model \\
\hline \multicolumn{5}{|l|}{ Study design: } \\
\hline RDBPCT & 45 & 1.00 (0.98 to 1.02$)$ & 46 & Fixed effects \\
\hline OLRCT & 5 & 0.98 (0.89 to 1.07$)$ & 0 & Fixed effects \\
\hline \multicolumn{5}{|l|}{ Methodological quality: } \\
\hline High quality (Jadad score 5) & 24 & 0.99 (0.96 to 1.03$)$ & 45 & Fixed effects \\
\hline Low quality (Jadad score $\leq 4$ ) & 23 & 1.01 (0.98 to 1.03$)$ & 32 & Fixed effects \\
\hline \multicolumn{5}{|l|}{ Duration of treatment (years): } \\
\hline$<5$ & 34 & 0.97 (0.90 to 1.04$)$ & 52 & Random effects \\
\hline$\geq 5$ & 16 & 1.01 (0.98 to 1.03$)$ & 0 & Fixed effects \\
\hline \multicolumn{5}{|l|}{ Funding source: } \\
\hline Pharmaceutical industry & 5 & $1.01(0.96$ to 1.07$)$ & 0 & Fixed effects \\
\hline Independent organisation & 42 & 1.00 (0.98 to 1.02$)$ & 42 & Fixed effects \\
\hline \multicolumn{5}{|l|}{ Supply source for supplements: } \\
\hline Pharmaceutical industry & 29 & 0.99 (0.97 to 1.02$)$ & 33 & Fixed effects \\
\hline Not pharmaceutical industry & 18 & 1.01 (0.98 to 1.05$)$ & 47 & Fixed effects \\
\hline \multicolumn{5}{|l|}{ Type of control: } \\
\hline Placebo & 44 & 1.00 (0.98 to 1.02$)$ & 46 & Fixed effects \\
\hline No placebo & 6 & 0.97 (0.89 to 1.06$)$ & 0 & Fixed effects \\
\hline \multicolumn{5}{|l|}{ No of participants in each trial: } \\
\hline$<10000$ & 40 & $0.97(0.94$ to 1.01$)$ & 40 & Fixed effects \\
\hline$\geq 10000$ & 10 & $1.02(0.99$ to 1.04$)$ & 39 & Fixed effects \\
\hline
\end{tabular}


Table 5| Efficacy of vitamin and antioxidant supplements given singly or combined with other vitamin or antioxidant supplements in prevention of major cardiovascular events in subgroup meta-analysis

\begin{tabular}{|c|c|c|c|c|}
\hline Factor & No of trials & Relative risk (95\% Cl) & Heterogeneity, $I^{2}(\%)$ & Model \\
\hline All & 50 & $1.00(0.98$ to 1.02$)$ & 42 & Fixed effects \\
\hline \multicolumn{5}{|l|}{ Vitamin A: } \\
\hline Given singly & NA & - & - & - \\
\hline Combined with others & 2 & 0.98 (0.45 to 2.16$)$ & 87 & Random effects \\
\hline \multicolumn{5}{|l|}{ Vitamin $\mathrm{B}_{6}$ : } \\
\hline Given singly & NA & - & - & - \\
\hline Combined with others & 16 & $0.96(0.92$ to 1.01$)$ & 33 & Fixed effects \\
\hline Low quality trials & 5 & $0.94(0.73$ to 1.21$)$ & 66 & Random effects \\
\hline High quality trials & 11 & 0.96 (0.91 to 1.01$)$ & 1 & Fixed effects \\
\hline \multicolumn{5}{|l|}{ Vitamin $\mathrm{B}_{12}$ : } \\
\hline Given singly & NA & - & - & - \\
\hline Combined with others & 17 & 0.99 (0.95 to 1.02$)$ & 37 & Fixed effects \\
\hline Low quality trials & 5 & 0.94 (0.73 to 1.21$)$ & 66 & Random effects \\
\hline High quality trials & 12 & 0.98 (0.95 to 1.02$)$ & 18 & Fixed effects \\
\hline \multicolumn{5}{|l|}{ Folic acid: } \\
\hline Given singly & 4 & $1.02(0.84$ to 1.23$)$ & 47 & Fixed effects \\
\hline Combined with others & 17 & 0.99 (0.95 to 1.02$)$ & 37 & Fixed effects \\
\hline Given singly or combined & 21 & 0.99 (0.95 to 1.02$)$ & 35 & Fixed effects \\
\hline Low quality trials & 8 & 0.99 (0.90 to 1.08$)$ & 49 & Fixed effects \\
\hline High quality trials & 12 & 0.98 (0.95 to 1.02$)$ & 18 & Fixed effects \\
\hline \multicolumn{5}{|l|}{ Vitamin $C^{*}:$} \\
\hline Given singly & NA & - & - & - \\
\hline Combined with others & 7 & 0.99 (0.94 to 1.06$)$ & 16 & Fixed effects \\
\hline Low quality trials & 4 & 0.99 (0.94 to 1.04$)$ & 44 & Fixed effects \\
\hline High quality trials & 3 & $0.99(0.88$ to 1.11$)$ & 0 & Fixed effects \\
\hline \multicolumn{5}{|l|}{ Vitamin D } \\
\hline Given singly & 2 & $0.95(0.86$ to 1.05$)$ & 11 & Fixed effects \\
\hline Combined with others & 5 & $1.04(0.99$ to 1.10$)$ & 0 & Fixed effects \\
\hline Given singly or combined & 7 & $1.02(0.98$ to 1.07$)$ & 23 & Fixed effects \\
\hline Low quality trials & 5 & $1.02(0.98$ to 1.08$)$ & 47 & Fixed effects \\
\hline High quality trials & 2 & 1.01 (0.45 to 2.27$)$ & 0 & Fixed effects \\
\hline \multicolumn{5}{|l|}{ Vitamin $E^{\star}:$} \\
\hline Given singly & 10 & 0.93 (0.85 to 1.01$)$ & 57 & Random effects \\
\hline Combined with others & 7 & 0.99 (0.94 to 1.04$)$ & 15 & Fixed effects \\
\hline Given singly or combined & 17 & 0.97 (0.94 to 1.01$)$ & 44 & Fixed effects \\
\hline Low quality trials & 9 & 0.99 (0.95 to 1.03$)$ & 43 & Fixed effects \\
\hline High quality trials & 8 & $0.95(0.90$ to 1.00$) \dagger$ & 45 & Fixed effects \\
\hline \multicolumn{5}{|l|}{$\beta$ carotene: } \\
\hline Given singly & 5 & $1.02(0.96$ to 1.08$)$ & 31 & Fixed effects \\
\hline Combined with others & 6 & 1.00 (0.81 to 1.23$)$ & 70 & Random effects \\
\hline Given singly or combined & 11 & 1.04 (0.96 to 1.12$)$ & 55 & Random effects \\
\hline Low quality trials & 6 & 0.99 (0.95 to 1.03$)$ & 30 & Fixed effects \\
\hline High quality trials & 5 & $1.13(0.98$ to 1.29$)$ & 64 & Random effects \\
\hline \multicolumn{5}{|l|}{ Selenium: } \\
\hline Given singly & 3 & 0.34 (0.06 to 2.05$)$ & 70 & Random effects \\
\hline Combined with others & 4 & $0.88(0.72$ to 1.08$)$ & 26 & Fixed effects \\
\hline Given singly or combined & 7 & 0.91 (0.77 to 1.06$)$ & 47 & Fixed effects \\
\hline Low quality trials & 4 & 0.91 (0.73 to 1.12$)$ & 43 & Fixed effects \\
\hline
\end{tabular}




\section{Table 5 (continued)}

\begin{tabular}{|c|c|c|c|c|}
\hline Factor & No of trials & Relative risk $(95 \% \mathrm{Cl})$ & Heterogeneity, $\mathrm{I}^{2}(\%)$ & Model \\
\hline High quality trials & 1 & $0.98(0.77$ to 1.24$)$ & NA & NA \\
\hline
\end{tabular}




\section{Figures}

Identified studies from the databases using keywords and bibliographies of relevant articles $(n=2240)$ :

PubMed $(n=528)$, Embase $(n=682)$, Cochrane Library $(n=408)$, Scopus $(n=570)$, CINAHL $(n=18)$,

ClinicalTrials.gov $(n=13)$, and bibliographies $(n=21)$

$\longrightarrow \quad$ Exclude duplicate articles $(n=573)$

Articles remaining after excluding duplicates $(n=1667)$

Exclude according to selection criteria ( $n=1593)$

Remaining articles, full text review $(n=74)$

Excluded articles $(n=24)$ :

Shared an identical population $(n=16)$

Not relevant study $(n=5)$

Reply or comments $(n=2)$

Insufficient data $(n=1)$

Trials included in final analysis $(n=50)$

Fig 1 Flow diagram for identification of relevant clinical trials examining effect of vitamins and supplements in prevention of cardiovascular disease 


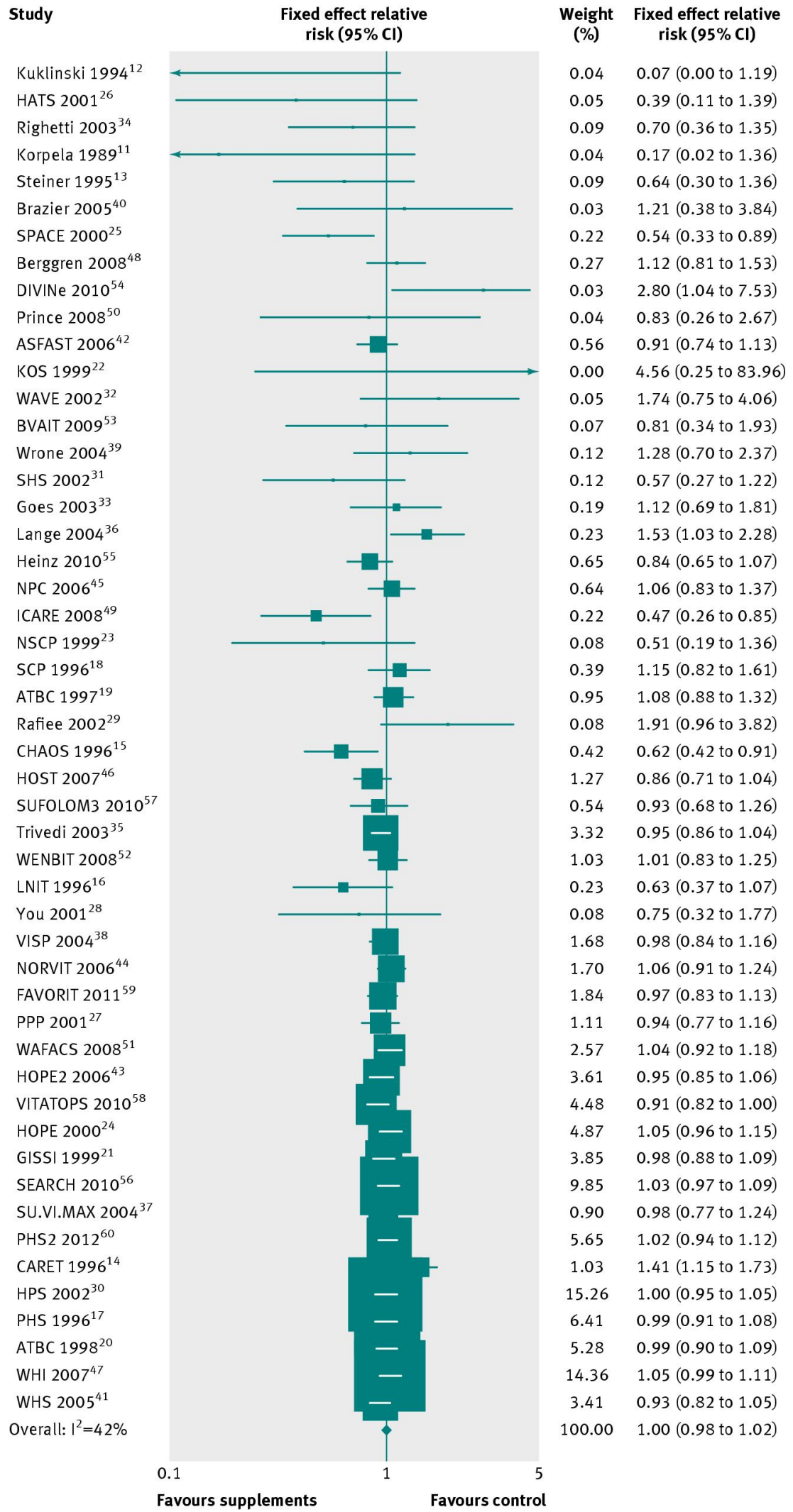

Fig 2 Efficacy of vitamin and antioxidant supplements in prevention of major cardiovascular events in meta-analysis of 50 randomised controlled trials sorted in ascending order of number of participants 


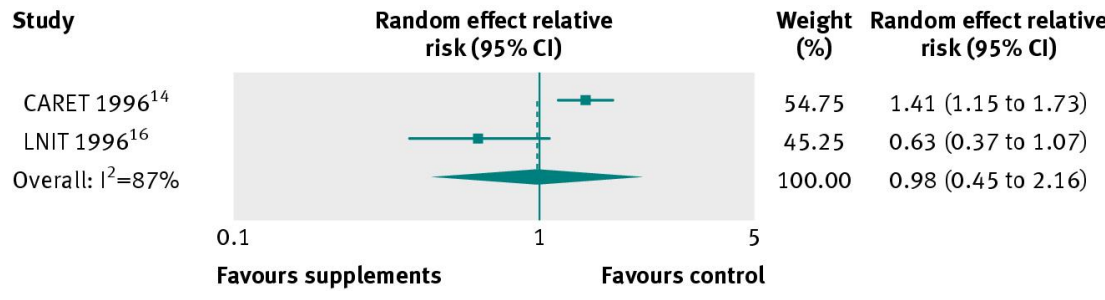

Fig 3 Efficacy of vitamin A supplements in prevention of major cardiovascular events in subgroup meta-analysis of randomised controlled trials 


\section{Study}

Vitamin $B_{6}(n=16)$ LNIT $1996^{16}$ SHS $2002^{31}$

Lange $2004^{36}$ VISP $2004^{38}$

Wrone $2004^{39}$ HOPE $22006^{43}$ NORVIT $2006^{44}$ HOST $2007^{46}$ WAFACS $2008^{51}$ WENBIT $2008^{52}$ BVAIT $2009^{53}$ DIVINe $2010^{54}$ Heinz $2010^{55}$ SUFOLOM3 $2010^{57}$ VITATOPS $2010^{58}$ FAVORIT $2011^{59}$ Overall: $\left.\right|^{2}=33 \%$

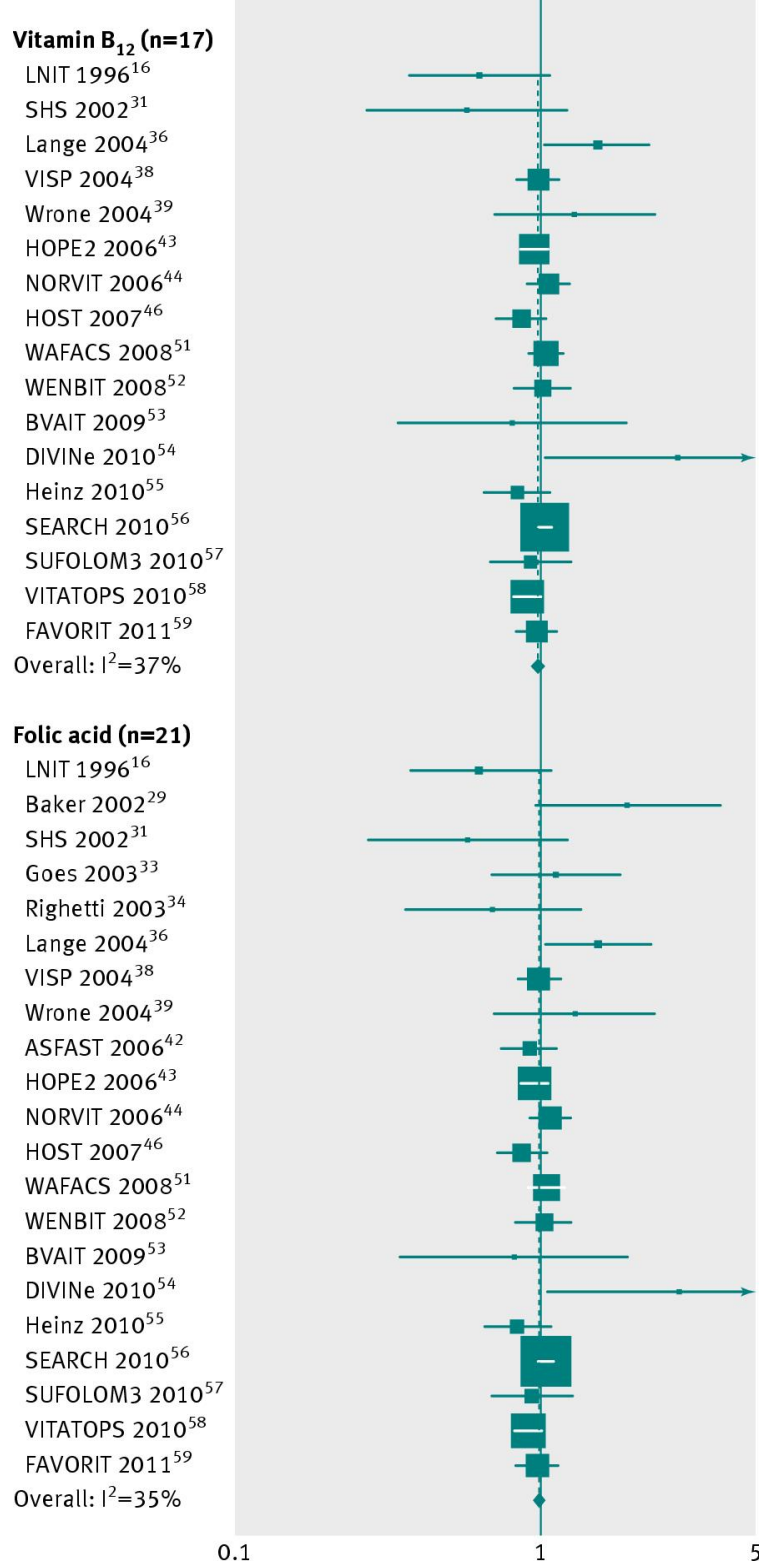

0.1

Favours supplements
Fixed effect relative risk $(95 \% \mathrm{Cl})$

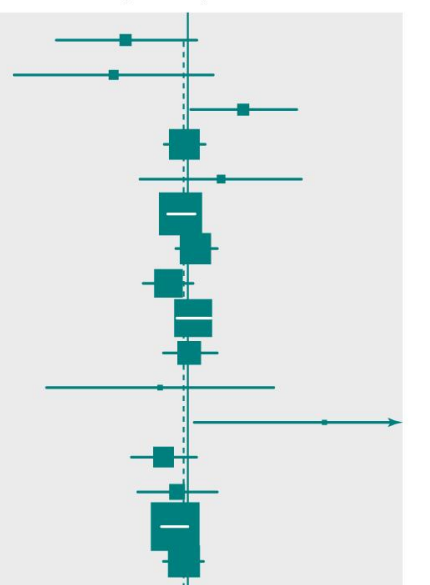
(\%)

1.14

0.58

1.14

8.35

0.57

17.89

8.43

6.28

12.77

5.09

0.36

0.16

3.23

2.67

22.23

9.11

100.00

0.77

0.39

0.76

5.61

0.38

12.01

5.66

4.22

8.58

3.42

0.24

0.11

2.17

32.83

1.79

14.93

6.12

100.00

0.75

0.26

0.38

0.60

0.30

0.74

5.44

0.37

1.82

11.66

5.49

4.09

8.32

$1.01(0.83$ to 1.25$)$

$0.24 \quad 0.81$ (0.34 to 1.93)

$0.11 \quad 2.80$ (1.04 to 7.53 )

$2.10 \quad 0.84$ (0.65 to 1.07$)$

$31.86 \quad 1.03$ (0.97 to 1.09 )

1.740 .93 (0.68 to 1.26 )

$14.490 .91(0.82$ to 1.00$)$

$5.93 \quad 0.97(0.83$ to 1.13$)$

$100.00 \quad 0.99(0.95$ to 1.02$)$

Fig 4 Efficacy of vitamins $B_{6}$ and $B_{12}$ and folic acid supplements in prevention of major cardiovascular events in subgroup meta-analysis of randomised controlled trials 


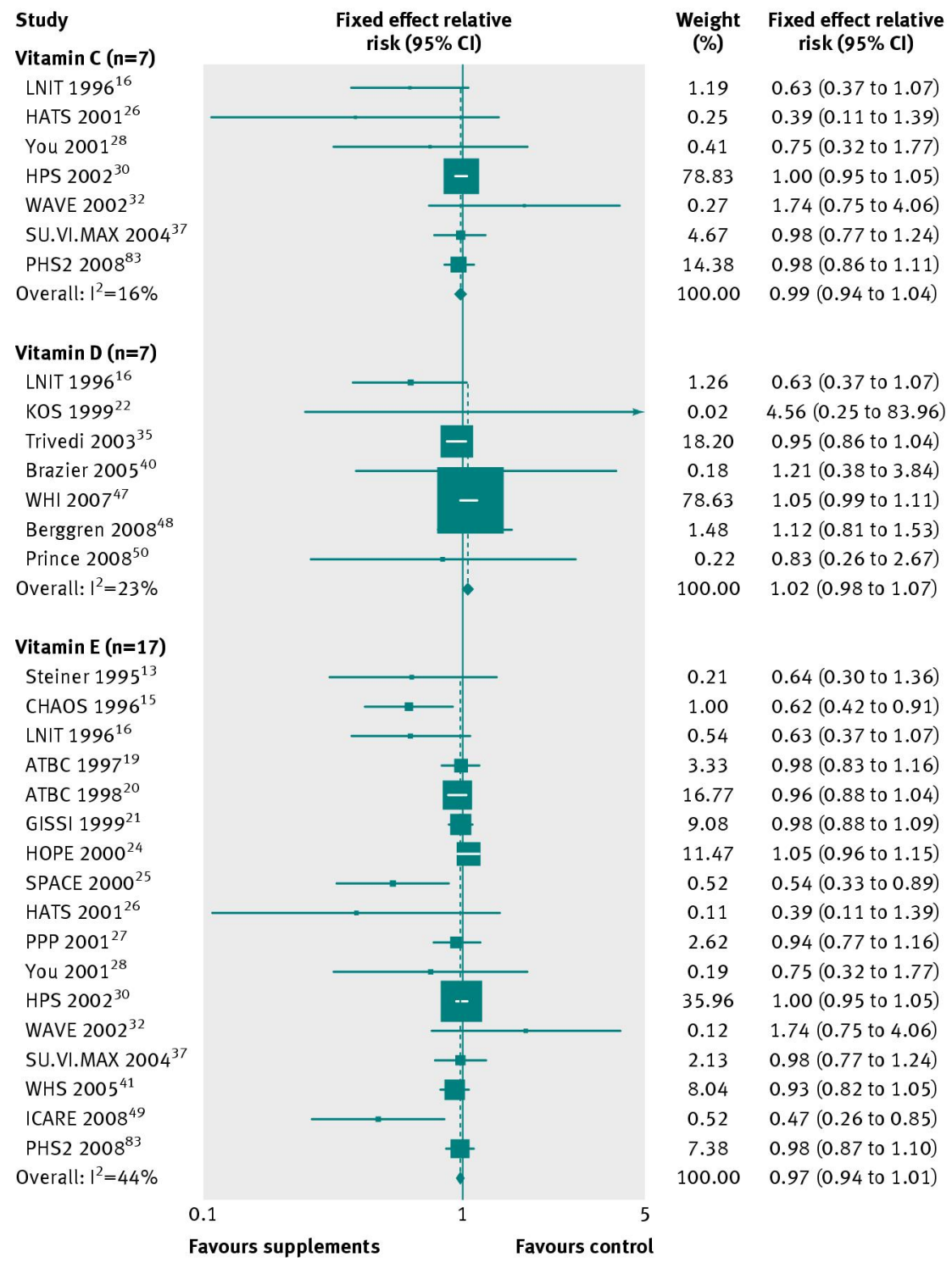

Fig 5 Efficacy of vitamins C, D, and E supplements in prevention of major cardiovascular events in subgroup meta-analysis of randomised controlled trials. For subgroup meta-analysis of vitamin C and vitamin E, we used data from 2008 PHS2 article $^{83}$ because data were not available in 2012 PHS article 


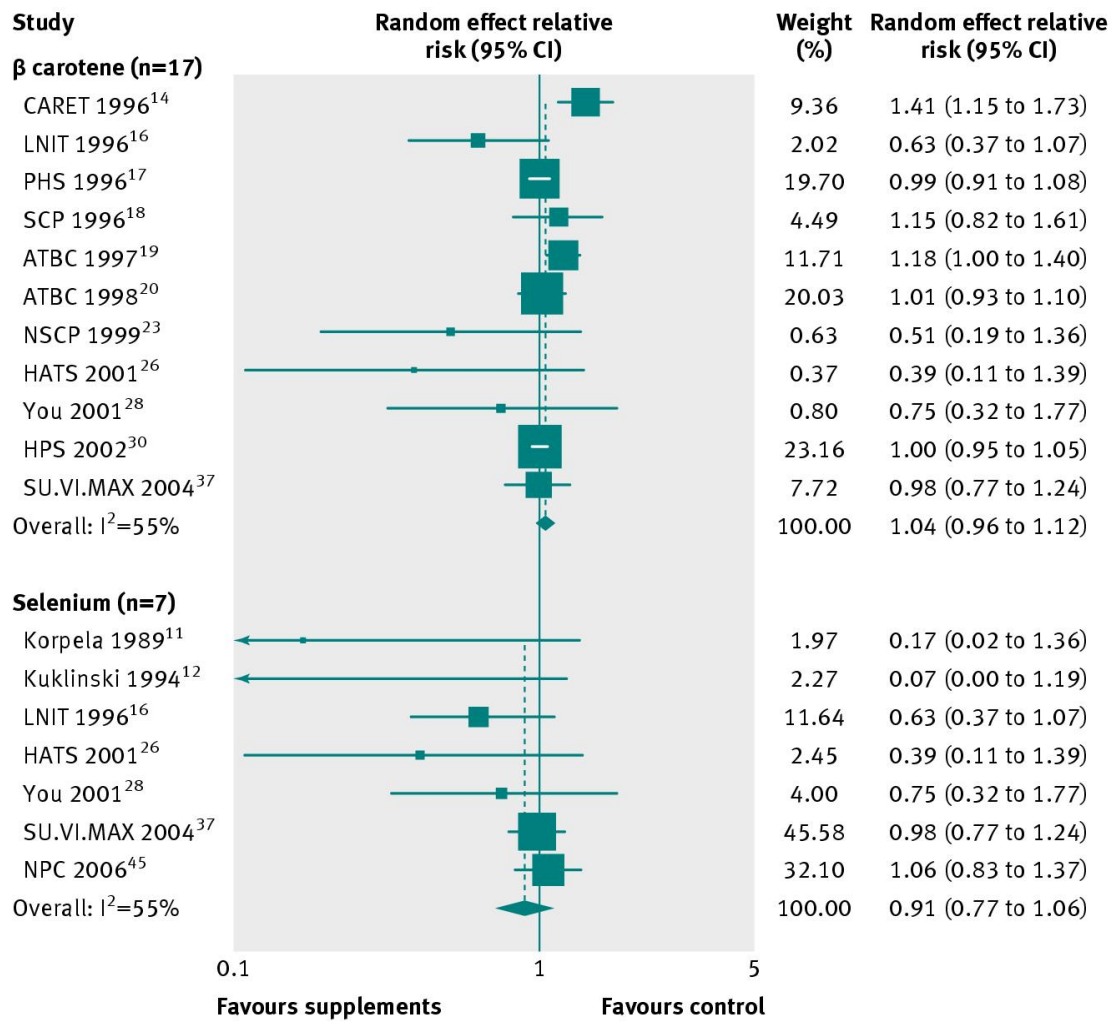

Fig 6 Efficacy of $\beta$ carotene and selenium supplements in prevention of major cardiovascular events in subgroup meta-analysis of randomised controlled trials

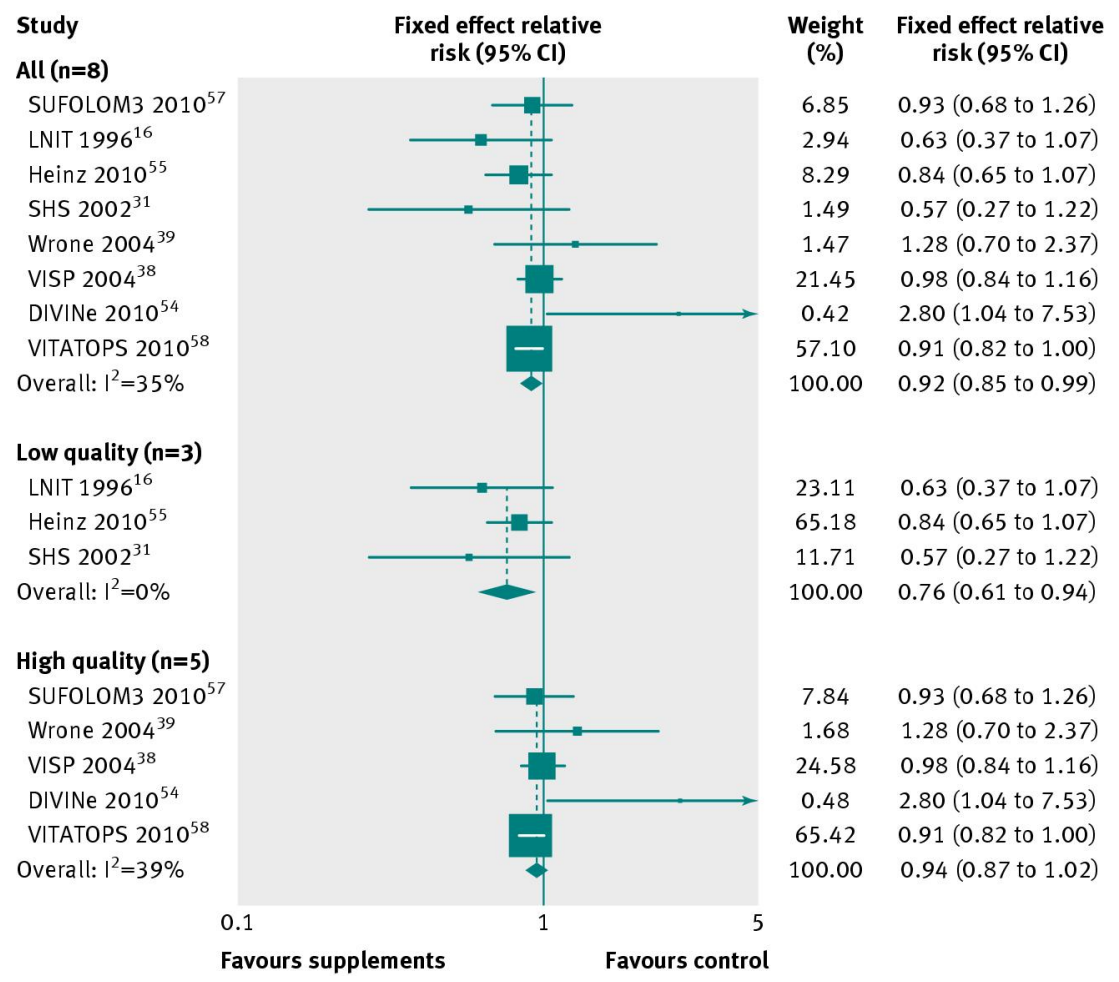

Fig 7 Efficacy of low dose vitamin $B_{6}$ supplements in prevention of major cardiovascular events in subgroup meta-analysis of randomised controlled trials by study quality according to Jadad scale 


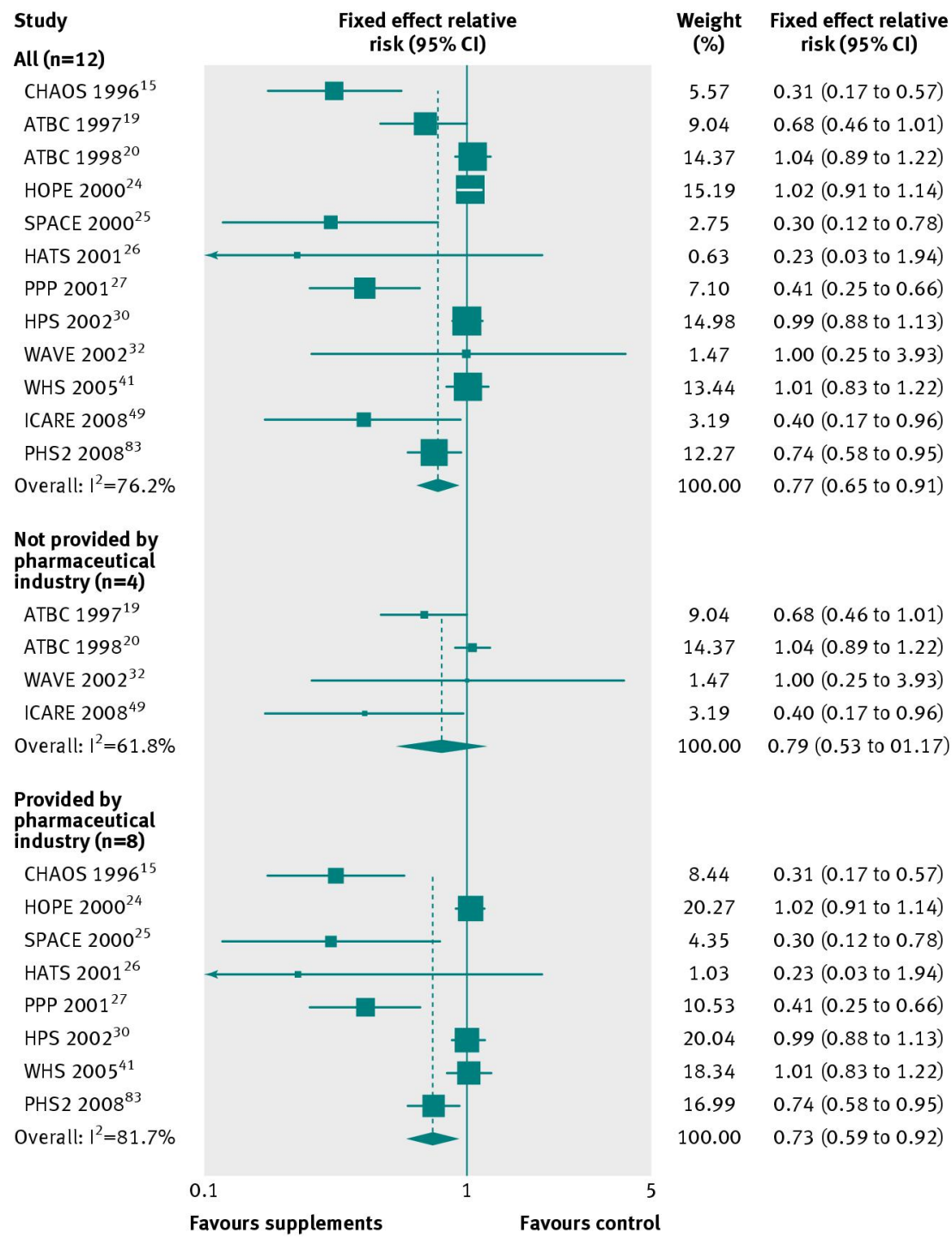

Fig 8 Efficacy of vitamin E supplements in prevention of myocardial infarction in subgroup meta-analysis of randomised controlled trials according to provider of supplements (pharmaceutical industry or other). For subgroup meta-analysis of vitamin E, we used data from 2008 PHS2 article ${ }^{83}$ because data were not available in 2012 PHS article 